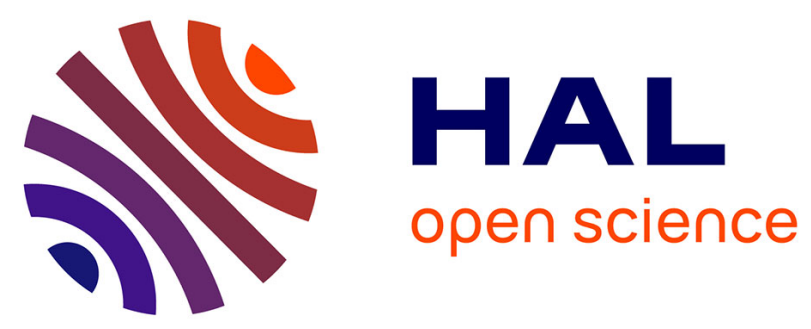

\title{
Les tombes néolithiques de Changis-sur-Marne Les Pétreaux (Seine-et-Marne) dans le contexte régional du Bassin parisien
}

Jean-Gabriel Pariat, Yolaine Maigrot, Françoise Lafage

\section{To cite this version:}

Jean-Gabriel Pariat, Yolaine Maigrot, Françoise Lafage. Les tombes néolithiques de Changis-sur-Marne Les Pétreaux (Seine-et-Marne) dans le contexte régional du Bassin parisien. Gallia Préhistoire - Préhistoire de la France dans son contexte européen, 2016, 56, pp.95-125. 10.4000/galliap.401 . hal-02342767

\section{HAL Id: hal-02342767 \\ https://hal.science/hal-02342767}

Submitted on 18 Dec 2019

HAL is a multi-disciplinary open access archive for the deposit and dissemination of scientific research documents, whether they are published or not. The documents may come from teaching and research institutions in France or abroad, or from public or private research centers.
L'archive ouverte pluridisciplinaire HAL, est destinée au dépôt et à la diffusion de documents scientifiques de niveau recherche, publiés ou non, émanant des établissements d'enseignement et de recherche français ou étrangers, des laboratoires publics ou privés.

\section{(ㅇ)(1) $\$$}

Distributed under a Creative Commons Attribution - NonCommercial - NoDerivatives $\mid 4.0$ 


\title{
Les tombes néolithiques de Changis-sur- Marne Les Pétreaux (Seine-et-Marne) dans le contexte régional du Bassin parisien
}

\author{
Jean-Gabriel PARIAT* \\ avec la collaboration de Yolaine MAIGrOt** \& Françoise LAFAGE ***
}

Mots cués. Néolithique moyen, Balloy, sépulture, inhumation.

Résumé. Un site de plaine alluviale de la basse vallée de la Marne a pu être suivi de façon exceptionnelle sur soixante-dix hectares entre 1995 et 2004 dans la carrière Cemex, qui exploite des granulats dans le double méandre d'Armentières en amont de Meaux. Cette fouille extensive préventive a révélé une multitude de traces d'occupations discontinues depuis le $V^{e}$ millénaire av. J.-C. jusqu'au Ive siècle ap. J.-C.Parmi elles, dix tombes furent fouillées et attribuées au Néolithique moyen II. Ce type de vestige, encore rare dans la moitié nord de la France, fait ici l'objet d'une présentation détaillée suivie d'une synthèse replaçant le site de Changis dans le contexte du Néolithique moyen régional.
Keywords. Middle Neolithic, Balloy, burial, inhumation.

Abstract. Between 1995 and 2004 quarrying by the aggregate extraction company Cemex over an area of seventy hectares in the double meander of Armentières upstream of Meaux provided an exceptional opportunity to investigate a site located in the floodplain of the lower Marne valley. This very large preventive excavation area revealed multiple traces of occupation of a site occupied intermittently from the $5^{\text {th }}$ millennium $B C$ to the $4^{\text {th }}$ century $A D$. Ten burials figure among the remains uncovered; they were excavated and dated to the Middle Neolithic II period. Such featuresremain a rare find in the northern half of France and are presented here in detail. A synthesis, which sets the site of Changis in its Middle Neolithic regional context concludes the article.

* Service Départemental d'Archéologie du Val d'Oise et UMR 7206 - Ecoanthropologie et Ethnobiologie, Abbaye de Maubuisson, rue Richard de Tour, 95310 Saint-Ouen-l'Aumône, jean-gabriel.pariat@ valdoise.fr

**UMR TRAJECTOIRES, Maison René-Ginouvès, 21, allée de l'Université, 92023 Nanterre cedex, yolaine.maigrot@mae.u-paris10.fr *** INRAP, UMR TRAJECTOIRES - équipe Protohistoire européenne, Maison René-Ginouvès,21, allée de l’Université, 92023 Nanterre cedex, francoise.lafage@inrap.fr 
La commune de Changis-sur-Marne est localisée dans la basse vallée de la Marne, dans le sud du département de la Seine-et-Marne, entre Meaux et la Ferté-sous-Jouarre. Les terrains soumis à une approche archéologique sont situés à $1 \mathrm{~km}$ au nord-ouest de la commune, en rive droite de la Marne (fig. 1).

À cet endroit une large nappe alluviale ancienne et récente est venue sceller le gisement. Les terrains, exposés au sud, décrivent une pente douce et sont recouverts d'alluvions récentes. Différentes ressources naturelles sont disponibles dans les environs immédiats (eau, silex, grès etc.). Ainsi le contexte se prête particulièrement à des implantations humaines au cours du temps. Les découvertes archéologiques se sont d'ailleurs multipliées dans ce secteur de la basse vallée de la Marne au cours des quinze dernières années (Lanchon et al., 2008).

La rive gauche, qui fait face au site, est abrupte et boisée. Elle repose sur des formations du Bartonien inférieur à banc de grès et à galets de silex, ainsi que du Bartonien moyen à calcaire et marnes.

Le site est inégalement érodé. Dans l'ensemble la terre végétale recouvre trois types de dépôts sédimentaires. Le sommet de la butte ancienne est totalement à nu. La partie médiane se caractérise par des colluvions limoneuses brunrouge surmontant partiellement un limon brun plus ancien, à la base duquel a notamment été caractérisé la plupart des vestiges d'époque néolithique. La partie basse correspond à un sédiment compacté recouvert d'une couche de limon de débordement.

Les terrains explorés, aux lieux-dits Les Pétreaux et Le Dessus de la Chaussée, se trouvaient dans l'emprise d'une carrière de granulats de 125 ha, exploitée depuis 1988 (Morillon-Corvol puis CEMEX). Surveillés dès 1992 par le
Service Régional de l'Archéologie d'Île-de-France, ils firent l'objet d'une fouille pluriannuelle préalablement à l'exploitation de la sablière à partir de 1995. Les travaux furent coordonnés par F. Lafage entourée d'une équipe pluridisciplinaire. La fouille s'est achevée en 2004.

En 10 ans, 70 hectares furent sondés révélant une multitude de traces d'occupation. Les plus anciennes renvoient au $\mathrm{V}^{\mathrm{e}}$ millénaire av. J.-C., tandis que les plus récentes datent du $\mathrm{IV}^{\mathrm{e}}$ siècle ap. J.-C. (Lafage et al., 2006). Une équipe de spécialistes travaille sur les différentes occupations mises en évidence (Lafage et al., 2006 ; Lafage et al., 2007 ; Lanchon et al., 2008).

Le champ des pratiques funéraires néolithiques est illustré à Changis par la découverte de tombes rattachées au $\mathrm{IV}^{\mathrm{e}}$ millénaire av. J.-C. Leur mise au jour fut régulière au cours de la fouille à un rythme moyen d'une tombe par campagne. Plusieurs archéologues spécialisés dans l'étude des pratiques funéraires ont apporté leur concours à l'étude de ces sépultures que ce soit sur le terrain ou en laboratoire : V. Delattre, P. Chambon, J.-G. Pariat et C. Thévenet. À partir de 2002, J.-G. Pariat supervisa l'étude de cet ensemble qui fit l'objet d'une présentation sommaire en 2002, alors que les opérations de terrain n'étaient pas terminées (Pariat, 2002). Une autre contribution, plus thématique, fut réalisée lors d'un colloque portant sur les coffres du Néolithique moyen occidental (Pariat, 2007a). Les analyses complémentaires (datations radiocarbones, étude de la céramique) sont aujourd'hui terminées et il est donc possible de publier cet ensemble de sépultures, par bien des aspects singulier au sein du Néolithique moyen régional.

À l'heure actuelle, les ossements et le mobilier provenant des tombes néolithiques de Changis sont regroupés avec les autres vestiges du site, dans le dépôt de la Société Historique et

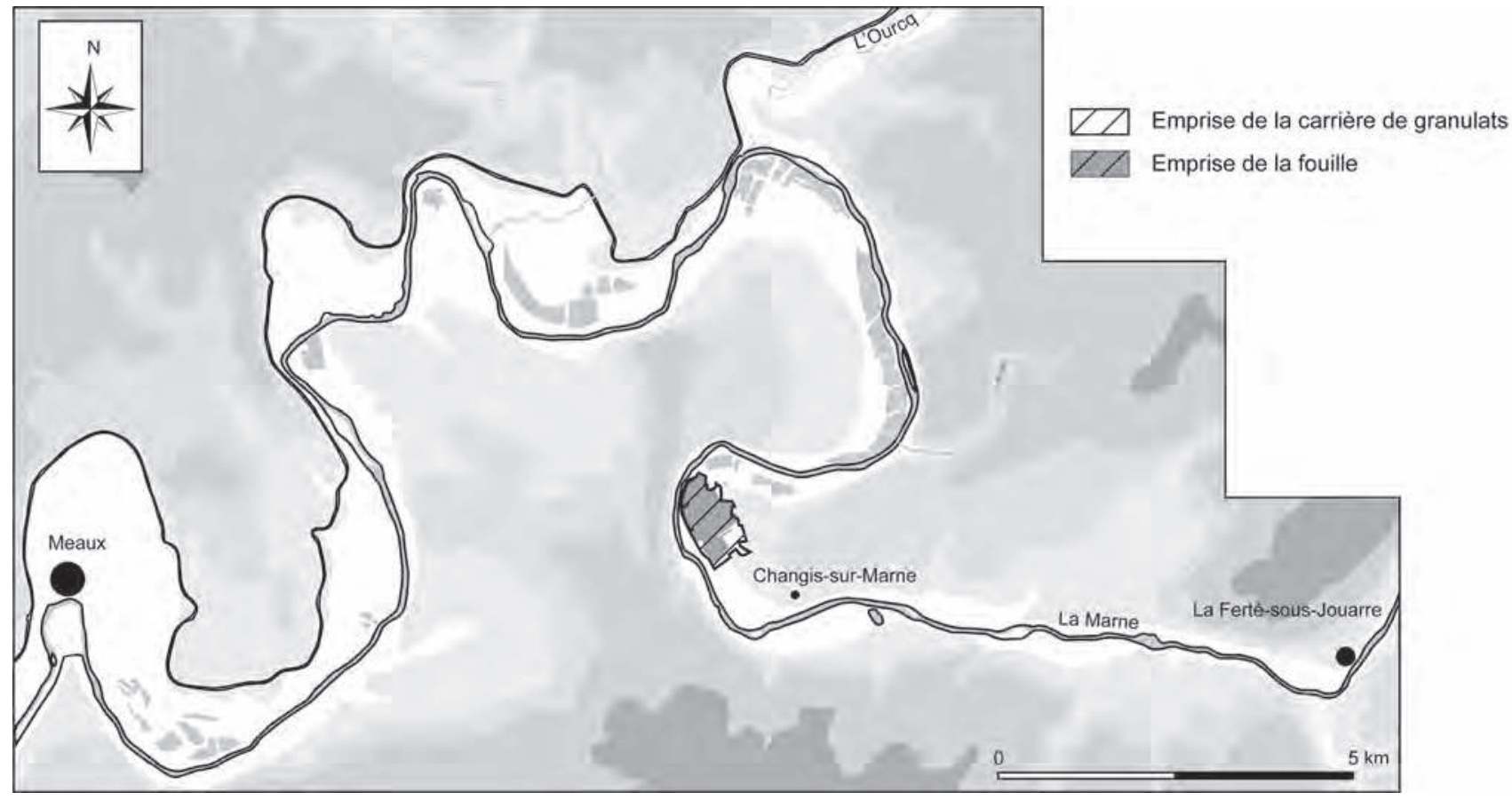

Fig. 1 - Changis-sur-Marne Les Pétreaux, Le Dessus de la Chaussée, localisation du site (DAO : I. Praud, INRAP).

Changis-sur-Marne Les Pétreaux, Le Dessus de la Chaussée, site location (graphics: I. Praud, INRAP). 
Archéologique de Lagny-sur-Marne et ses Environs (SHALE), situé sous l'actuel marché couvert à Lagny-sur-Marne (Seineet-Marne). Les ossements sont conditionnés dans des bacs en plastique. Seule la tombe 18 est manquante, victime des nombreux déménagements dont a fait l'objet cette série, et doit être considérée comme perdue.

\section{PRÉSENTATION ET ANALYSE DES STRUCTURES}

À l'issue de la fouille, seize tombes étaient provisoirement rattachées au Néolithique moyen. Dix d'entre elles ont pu être attribuées avec certitude à cette période soit parce qu'elles renfermaient un mobilier caractéristique soit parce qu'elles furent datées par le radiocarbone (tabl. I). Les six sépultures restantes n'ont pas livré de mobilier et n'ont pas fait l'objet d'une datation. Nous considérons donc leur rattachement au Néolithique moyen comme étant probable ou possible, sans toutefois en tenir compte dans la suite du développement.

Les dix sépultures analysées dans cet article se répartissaient sur une très grande surface englobant pratiquement toute la longueur de l'emprise du nord vers le sud (fig. 2). Aucune d'entre elles n'a été retrouvée sur le sommet de la butte ancienne à l'est. Toutes sont apparues à mi-pente ou en base de pente vers l'ouest. Deux tombes, les sépultures 5 et 23, sont isolées au nord. Un tissu plus lâche est formé dans la partie centrale de l'emprise par les tombes 11, 14, 18, 19, 20, 21 et 22. Enfin la sépulture 31 est à l'écart au sud. La distance entre les tombes 23 et 31, qui sont les plus éloignées l'une de l'autre, est de $1 \mathrm{~km}$ environ.

\section{PRÉAMBULE MÉTHODOLOGIQUE}

Cette section est consacrée à une présentation succincte des différentes méthodes d'analyse employées lors de l'étude de l'ensemble funéraire de Changis.

\section{DÉMARCHE}

Toutes les sépultures sont décrites selon une grille unique. Après une description des fosses sépulcrales, des informations relatives aux inhumés et à leur état de conservation sont exposées. Puis une description des connexions et des dislocations est effectuée afin de mettre en évidence le milieu de décomposition des corps et d'éventuels dispositifs sépulcraux. Enfin le mobilier recueilli est décrit et analysé.

L'analyse taphonomique se fonde sur les travaux précurseurs de F. Poplin (1975), par la suite largement théorisés par H. Duday $(1995,2005)$. Il s'agit notamment d'identifier, dans une tombe ce qui relève des processus naturels, et ce qui au contraire procède de l'activité volontaire des hommes, autrement dit des gestes funéraires, les ossements humains retrouvés témoignant des nombreuses interactions survenues entre les différents éléments constitutifs de la tombe.

\section{LA DIAGNOSE SEXUELLE}

Un dimorphisme sexuel s'exprime au niveau du bassin sur le squelette humain adulte, car l'os coxal constitue à la fois le siège de la parturition et une adaptation à la bipédie (Bruzek, 2002). Ce type d'os permet un taux de détermination à $95 \%$, la prise en compte d'autres ossements n'améliorant pas la fiabilité du résultat (Bruzek et Ferembach, 1992).

\begin{tabular}{|c|c|c|c|}
\hline$N^{\circ}$ sep $\quad$ Datation & Néolithique moyen & Néolithique? & Fiabilité* $^{*}$ \\
\hline 23 & oui & & 0 \\
\hline 31 & oui & & 0 \\
\hline 14 & oui & & 0 \\
\hline 11 & oui & & 0 \\
\hline 20 & oui & & 0 \\
\hline 5 & oui & & 0 \\
\hline 21 & oui & & 0 \\
\hline 22 & oui & & 0 \\
\hline 19 & oui & & 0 \\
\hline 18 & oui & & 0 \\
\hline 9 & & oui & 2 \\
\hline 7 & & oui & 2 \\
\hline 12 & & oui & 1 \\
\hline 16 & & oui & 2 \\
\hline 3 & & oui & 2 \\
\hline 17 & & oui & 2 \\
\hline
\end{tabular}

* La fiabilité de la datation a été hiérarchisée du plus fiable (0) au moins fiable (2)

Tabl. I - Inventaire des tombes néolithiques certaines et probables de Changis-sur-Marne. 


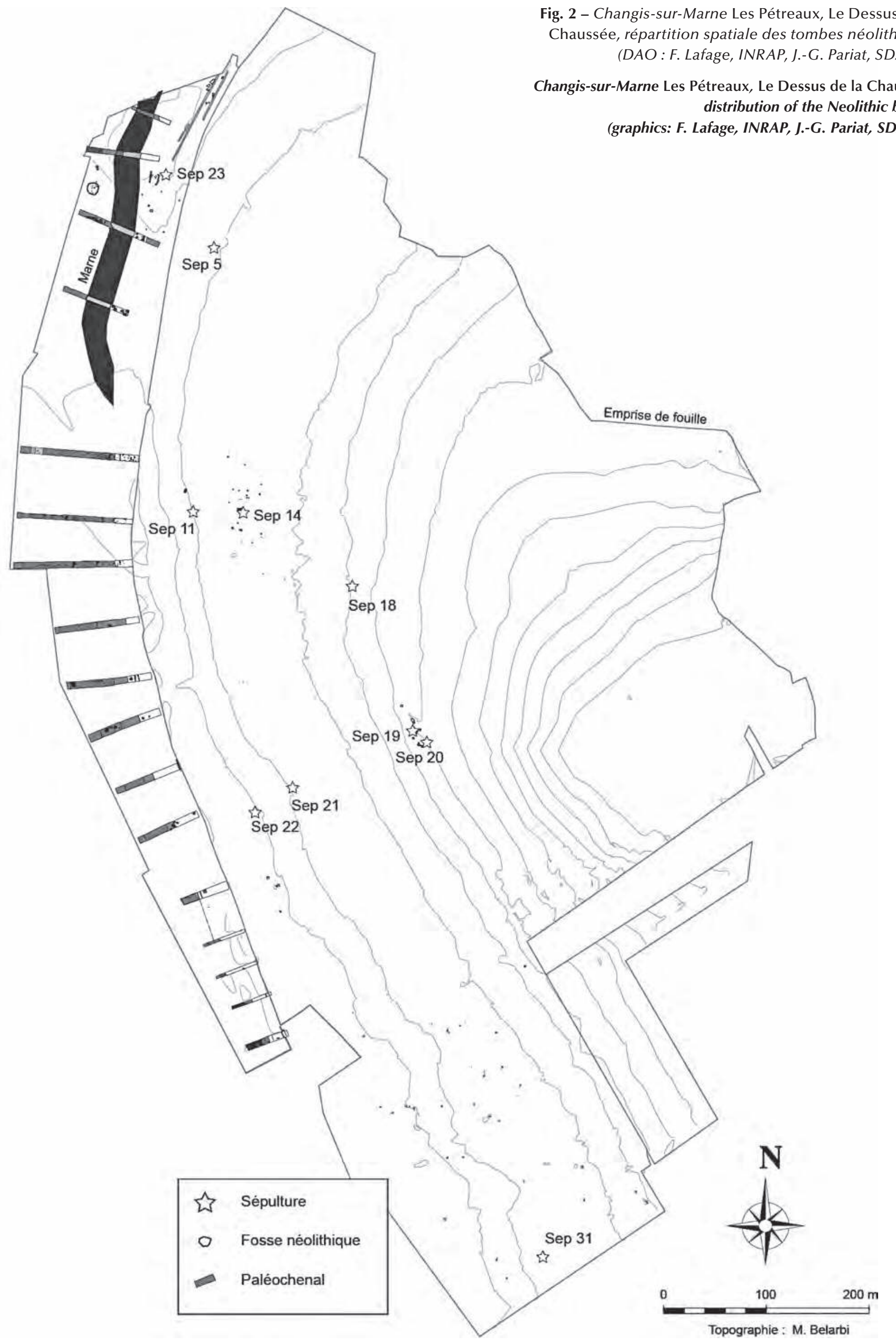


Deux méthodes ont été utilisées sur la série de Changis, car elles permettent de prendre en compte des restes fragmentés : la méthode morphoscopique fondée sur l'examen de cinq caractères reflétant l'ensemble du dimorphisme sexuel (Bruzek, 2002), et la méthode métrique qui s’appuie sur des fonctions discriminantes élaborées à partir de trois segments fonctionnels de l'os coxal (Murail et al., 2005).

En l'absence de l'os coxal et chez les individus immatures, le sexe n'a pas été déterminé.

\section{L'ESTIMATION DE l'ÂGE AU DÉCÈs}

Dans l'ensemble, les processus de maturation et de croissance osseuse offrent des indicateurs d'âge particulièrement fiables quand les sujets sont jeunes (Bruzek et al., 1997).

Pour le seul tout-petit de la série, les tables de croissance publiées par L. Scheuer et S. Black (2000) ont été utilisées, car elles permettent une estimation de l'âge pour chaque os. Dans le cas des enfants, ce sont les diagrammes de développement dentaire élaborés par C.F.A. Moorrees, E.A. Fanning et E.E. Hunt (1963) qui ont été employés. Ils offrent l'avantage de permettre une estimation de l'âge pour chaque dent indépendamment, et ne nécessitent pas la conservation complète de la denture. Pour les adolescents, le recours à la maturation osseuse et plus particulièrement aux tableaux de R. Birkner (1980) permettant une estimation commune aux deux sexes a été pratiqué.

Enfin, chez les adultes, les processus de sénescence sont à l'origine de nombreuses méthodes d'estimation de l'âge. L'une d'elles, développée à partir d'une observation à l'œil nu de la surface auriculaire de l'ilium, a été employée sur la série de Changis (Schmitt, 2005), car cette partie de l'os coxal est particulièrement bien conservée dans les squelettes de la série.

\section{SÉPULTURE 5 (STRUCTURE 1026)}

\section{LA FOSSE ET SON COMBLEMENT}

La sépulture 5 se trouvait dans la partie nord occidentale de l'emprise de fouille, plutôt en bas de pente et à moins de $100 \mathrm{~m}$ de l'ancien chenal de la Marne. Elle se signalait en surface par une fosse au contour et au profil irrégulier dont le comblement limoneux brun foncé se distinguait nettement du substrat, et mesurait 2,30 m d'est en ouest par $1,70 \mathrm{~m}$ du nord au sud (fig. 3). Le creusement le plus profond, qui recelait des restes humains, était plus modeste : 1,20 m de long d'est en ouest et moins de $0,75 \mathrm{~m}$ de large. En coupe, son profil présentait des parois obliques et un fond irrégulier sur 0,40 m d'épaisseur.

Une couronne de blocs calcaires ou de grès suivait le contour de ce second creusement, aucun ossement n'outrepassant la limite ainsi définie.

\section{LES INHUMÉS}

Les restes de deux squelettes imbriqués furent identifiés sur le terrain, l'un d'eux (sujet A) occupant le tiers nord de la fosse, l'autre (sujet B) reposant sur les deux-tiers sud de la fosse. La position du sujet A, réduit, n'était pas observable a priori, alors que le sujet B était fléchi sur le côté droit, mains ramenées en avant de la face, tête au sud.

L'individu A était un adulte de sexe féminin âgé de plus de 50 ans tandis que l'individu B était un adulte de sexe masculin ayant entre 30 et 59 ans ou, plus de 40 ans.

L'état de conservation des vestiges humains était correct. Dans l'ensemble, les diaphyses et les épiphyses des os longs du sujet A présentaient une fragmentation plus conséquente que celles du sujet $B$. Une tempête survenue en début de fouille est à l'origine de dommages, car la serre qui protégeait la tombe bascula sur les vestiges engendrant notamment la fracturation du tibia gauche de l'individu B (non visible sur le relevé).

Si le squelette du sujet B pouvait apparaître de prime abord plus complet que celui de l'individu A, il n'en demeurait pas moins des déficits osseux conséquents, en particulier au niveau du thorax, de la colonne vertébrale, des pieds et des mains.

L'action répétée des labours et la pratique du sous-solage profond sont pour partie responsables de ces destructions, mais la cause principale des déficits s'explique par l'action des animaux fouisseurs.

\section{Connexions et dislocations}

La tête osseuse de l'individu A était disloquée, tout comme la plupart des ossements de ce sujet, regroupés dans le tiers sud de la fosse. Les quelques os de la cage thoracique, principalement des arcs de vertèbres lombaires apparaissaient à l'est, à l'opposé de la tête osseuse.

Les épaules étaient disloquées, à droite comme à gauche. Quant aux os des membres supérieurs, ils se trouvaient légèrement au sud et à l'est du bloc crânio-facial en fagots.

L'articulation de la hanche droite était distendue, à la différence de la gauche qui était disloquée. Enfin, les membres inférieurs étaient regroupés contre le bord nord, les os droits de la jambe et de la cheville ayant gardé un agencement cohérent.

La tête osseuse de l'individu B était en place, le crâne apparaissant par sa face latérale gauche et la mandibule demeurant en connexion avec celui-ci. La cage thoracique était disloquée. Seules les deux dernières vertèbres thoraciques et la première vertèbre lombaire avaient conservé des rapports anatomiques.

L'articulation de l'épaule droite était rompue et celle du coude était distendue. L'ulna croisait le radius qui apparaissait en face latérale. Les os du carpe étaient disloqués. À gauche la situation était comparable, la clavicule reposait sur la mandibule. La scapula en face postérieure était en connexion avec l'humérus. Les articulations du coude et du poignet étaient distendues.

Les os coxaux étaient sortis du volume initial du cadavre. À droite le genou avait peu bougé mais il manquait la patella, et la fibula s'était désolidarisée du tibia, qui se trouvait en face médiale légèrement postérieure. À gauche le fémur n'était plus à sa place et se trouvait en face antérieure avec la tête vers l'est au-dessus de la fibula droite. Les os des tarses droit et gauche étaient disloqués, un calcanéus apparaissant en arrière de la partie distale de la diaphyse du tibia droit. 


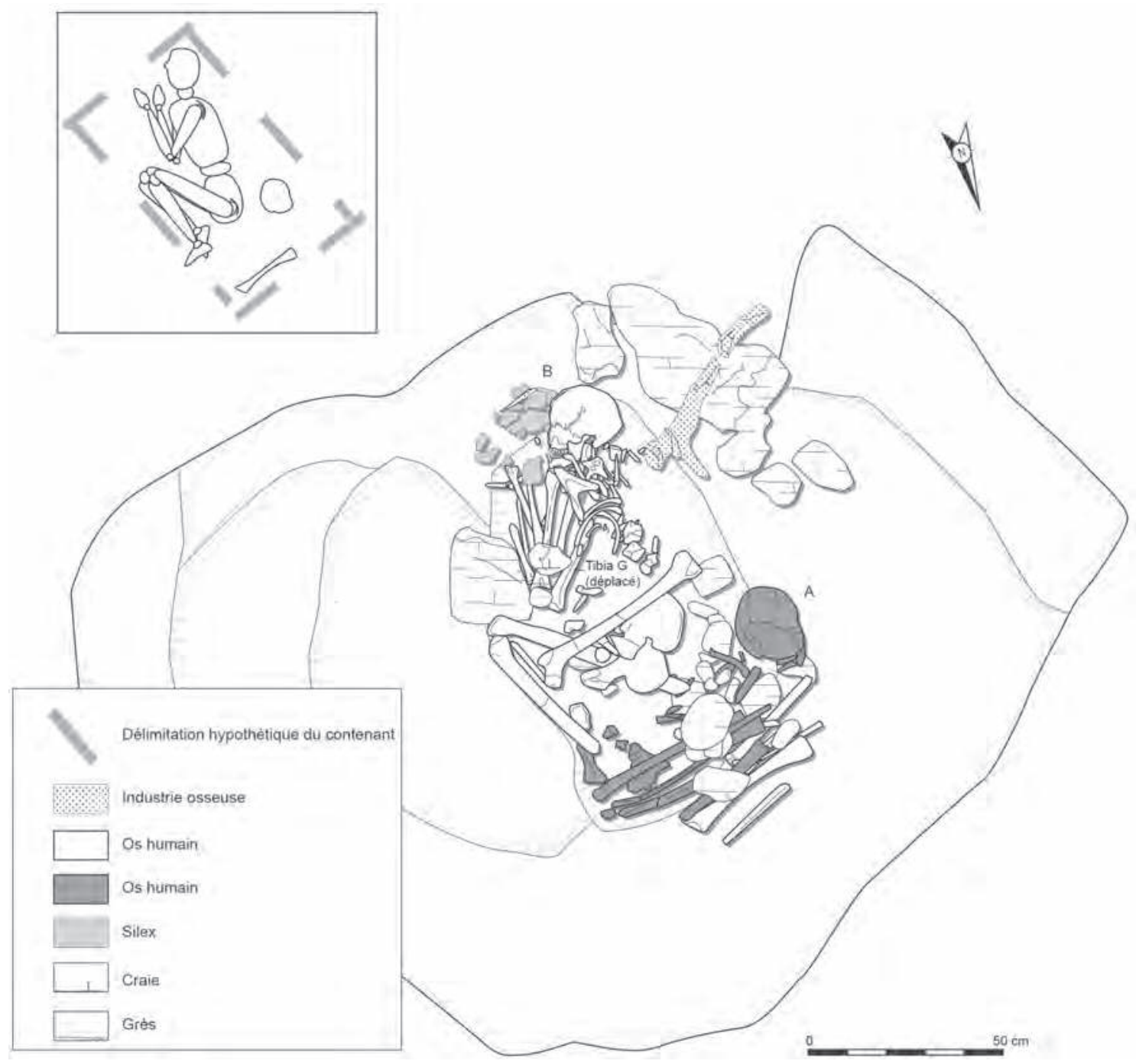

Fig. 3 - Changis-sur-Marne Les Pétreaux, Le Dessus de la Chaussée, plan de la sépulture 5 (DAO : J.-G. Pariat, SDAVO).

Changis-sur-Marne Les Pétreaux, Le Dessus de la Chaussée, plan of Burial 5 (graphics: J.-G. Pariat, SDAVO).

\section{Milieu de décomposition et tYPE de structure}

L'individu B s'est décomposé sur place. Mais le squelette du sujet A était-il un cadavre à son arrivée dans la tombe, ou bien un lot d'ossements déconnectés ? La répartition des différentes parties du squelette est cohérente du point de vue anatomique. Les membres inférieurs sont regroupés au nord, et les membres supérieurs au nord-est. Nous reprenons donc ici les conclusions formulées par V. Delattre (Lafage et Lanchon, 1998) : le squelette du sujet A appartient à un cadavre qui s'est décomposé in situ. Après décomposition le squelette a subi une réintervention. Il a été repoussé vers le nord, sans doute en vue du dépôt du sujet $B$.

Les arguments relatifs au milieu de décomposition abondent. Les ruptures d'articulation et les dislocations sont nombreuses au niveau du sujet B, ce qui trahit une évolution du corps au sein d'un espace vide. Cette hypothèse est confortée par la réintervention qu'a connu le sujet $\mathrm{A}$. La réduction n'a été possible que parce que l'espace sépulcral était accessible, donc vide et réouvrable.
Par conséquent, il faut envisager la présence d'un dispositif, ne serait-ce que pour l'aspect « réouvrable » du contenant. Cette sépulture est implantée dans une fosse, plus profonde et très étroite à l'emplacement des squelettes. Plusieurs blocs bordent ces derniers et leur disposition suggère un aménagement au contour quadrangulaire. Il pourrait bien s'agir d'un coffre ${ }^{1}$ en matière périssable, à en juger par l'exiguïté de la fosse.

\section{MOBILIER}

Différents vestiges mobiliers apparaissaient près de la tête de l'individu B. Outre un bois de massacre de cerf situé légèrement au-dessus de la tête, dans le comblement supérieur, un amas d'une quinzaine d'éclats en silex tertiaire au centre duquel

1. Un coffre est un contenant éventuellement mobile, potentiellement réouvrable destiné à accueillir un ou plusieurs sujets. Il doit être distingué du coffrage, contenant fixe par excellence, possiblement dépourvu de fond et dont les caractéristiques imposent un surdimensionnement de la fosse dès le creusement. 
se trouvait un outil appointé en os fut trouvé près de la face du sujet B au sud-est.

\section{Les éclats en silex}

Leétude des éclats a été réalisée par P. Bodu (Lafage et Lanchon, 1998). Issus d'affleurement de plaquette de silex tertiaire d'une seule origine, ce sont des éclats longs à partie proximale épaisse et partie distale fine. La percussion est réalisée à la pierre tendre (grès) ou au percuteur tendre (bois de cervidé) et fournit des éclats à la morphologie convexe. Cette série évoque très fortement des éclats de façonnage de pièce bifaciale ; tous appartiennent à la même chaîne opératoire mais interviennent à différents moments. Les éclats corticaux et sous corticaux proviennent du dégraissage et de la finition des convexités de la pièce bifaciale (deux types de talons, lisse ou abrasé). Sur quelques pièces, il manque la partie proximale. Cela signifie qu'il s'agit bien de pièces rapportées après un débitage extérieur, les parties proximales cassées au débitage étant restées sur les lieux de fabrication. Il n'a pas été possible de remonter entre elles les différentes pièces. Il s'agit sans doute d'une quinzaine de pièces présélectionnées provenant des déchets de fabrication d'une (ou plusieurs) hache(s). L'ensemble est stylistiquement homogène, ce qui corrobore l'idée de l'appartenance des éclats à une même activité, par exemple la fabrication d'une pièce bifaciale. Tous les éclats sont bruts de taille, en dehors d'un distal d'éclat large qui porte une retouche relativement marginale aménageant un front de grattoir.

\section{Les pièces osseuses}

À la sépulture $n^{\circ} 5$ sont associées deux pièces en matières dures animales : un outil appointé en os et une ramure de massacre presque complète (fig. 4).

L'outil appointé, qui mesure $112 \mathrm{~mm}$ de longueur pour une largeur maximale de $14 \mathrm{~mm}$, a été réalisé à partir d'un métatarse de cerf débité longitudinalement en quart par rainurage (fig. 4 , $n^{\circ} 1$ ). Le support obtenu a, par la suite, été façonné par abrasion. Les stries transversales, courtes, larges, profondes et légèrement courbes résultant de la mise en forme, indiquent que l'outil de travail utilisé était probablement un polissoir à main, au grain grossier et peu cimenté. La pièce est entière et présente, malgrés quelques traces éparses de radicelles, un excellent état de conservation de sa surface, aussi a-t-elle pu faire l'objet d'une analyse tracéologique. Macroscopiquement, 3 zones peuvent être individualisées (fig. 5) :

- La partie travaillante, où se concentre les traces liées $\mathrm{au}$ fonctionnement de l'outil et où les traces techniques ont totalement disparues,

- La partie mésiale, où les traces techniques restent le plus visibles,

- Enfin, la partie proximale, qui correspond à la zone de préhension où les traces techniques sont en partie effacées.

La partie active est bien délimitée et s'étend sur $1 \mathrm{~cm}$ depuis la pointe. L'extrémité présente un émoussé bien arrondi suggérant un contact avec une matière plutôt souple. Sous le microscope, on remarque que toutes les traces de mise en forme ont disparu au profit d'une surface douce, aux élévations bombées et de texture grenue (fig. $6, \mathrm{n}^{\circ} 1$ ). Elle est recouverte

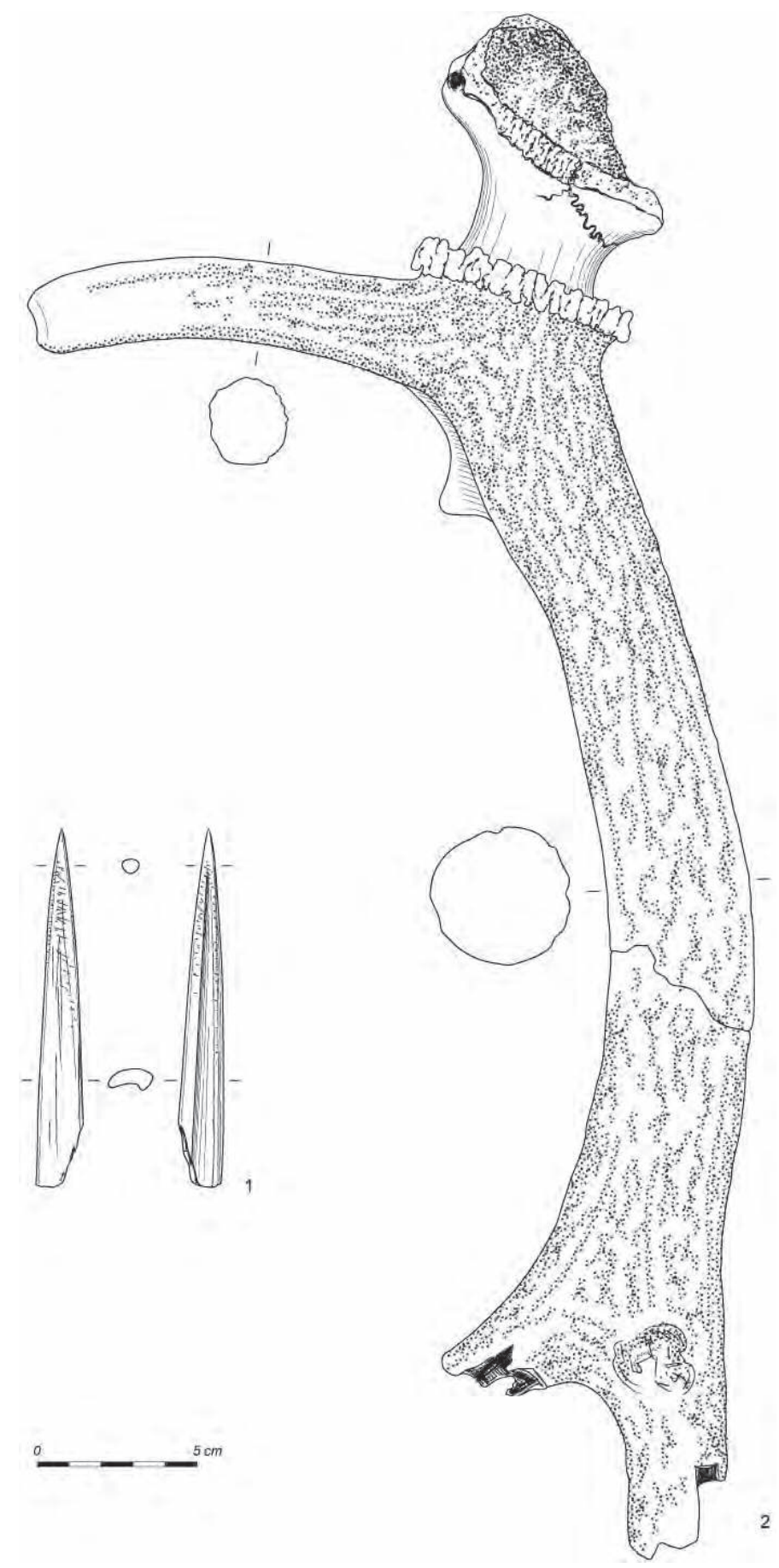

Fig. 4 - Changis-sur-Marne Les Pétreaux, Le Dessus de la Chaussée, matériel osseux associé à la sépulture $n^{\circ} 5$ de Changis-sur-Marne -1 : Pointe sur métapode de cerf ; 2 : Pic probable sur bois de massacre (illustration : Y. Maigrot, CNRS).

Changis-sur-Marne Les Pétreaux, Le Dessus de la Chaussée, bone associated with Burial 5. 1: point made from a deer metapodial; 2: probable pick made from antler of a killed deer (illustration: Y. Maigrot, CNRS).

d'un poli intrusif et brillant. Les stries y sont très nombreuses. Elles sont longues, fines à larges, leur bord est émoussé et leur fond est coalescent à l'exception des plus profondes. Elles sont entrecroisées et s'organisent transversalement à l'axe 


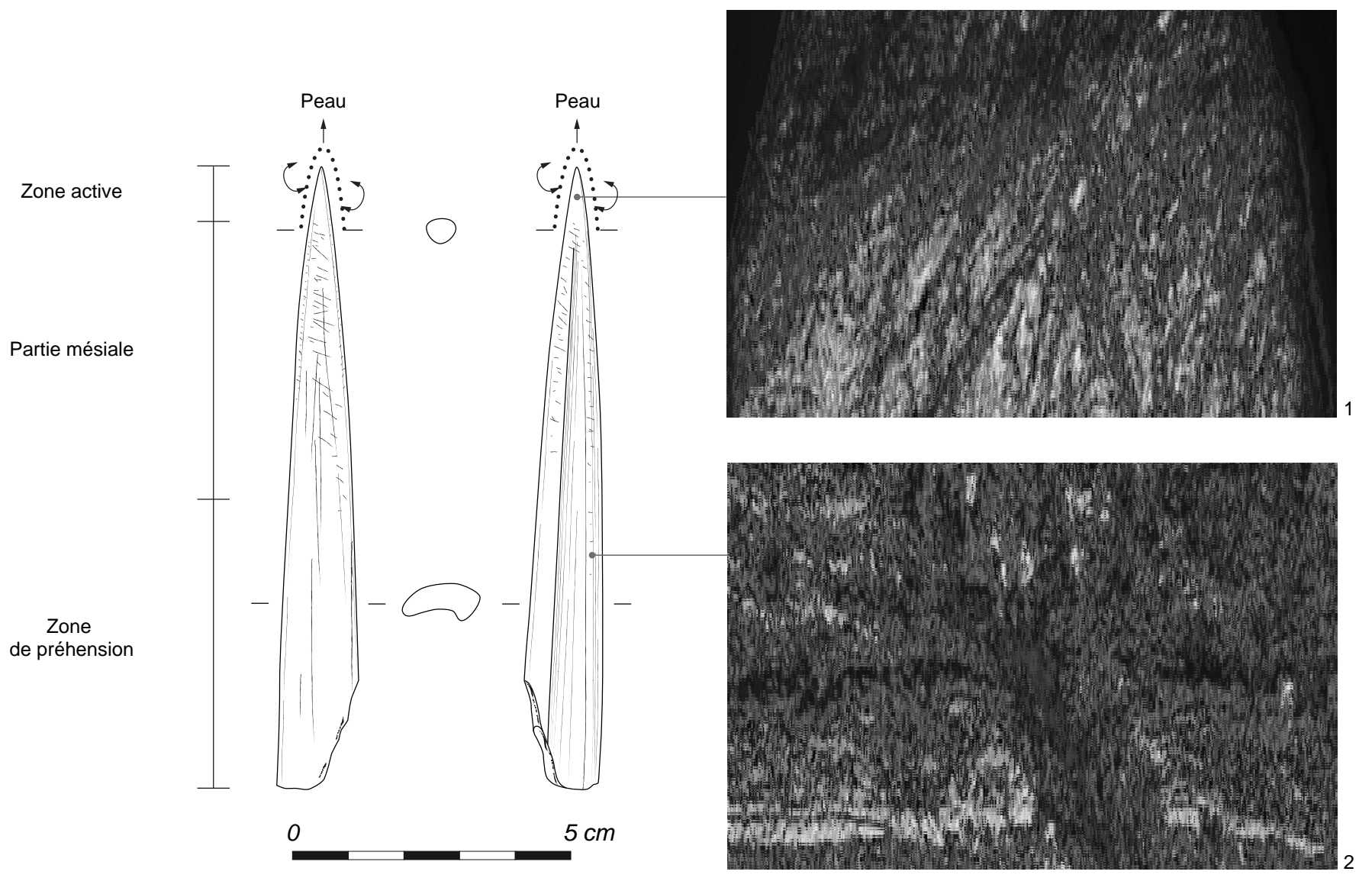

Fig. 5 - Changis-sur-Marne Les Pétreaux, Le Dessus de la Chaussée, détail des micro-surfaces observées sur l'outil en os de Changis interprété comme poinçon utilisé pour perforer la peau sèche (x200; illustration et cliché : Y. Maigrot, CNRS).

Changis-sur-Marne Les Pétreaux, Le Dessus de la Chaussée, detail of micro-surfaces observed on a bone tool from Changis interpreted as an awl used to pierce dried skins (magnification $\times 200$; illustration and photograph: Y. Maigrot, CNRS).

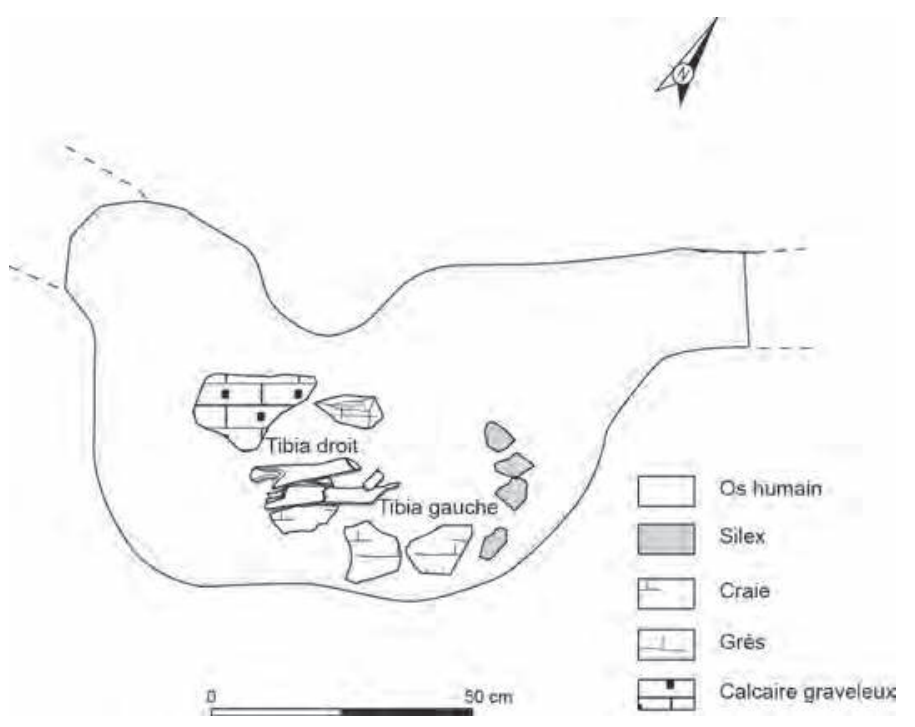

Fig. 6 - Changis-sur-Marne Les Pétreaux, Le Dessus de la Chaussée, plan de la sépulture 11 (DAO : F. Lafage INRAP, J.-G. Pariat, SDAVO).

Changis-sur-Marne Les Pétreaux, Le Dessus de la Chaussée, plan of Burial 11 (graphics: F. Lafage INRAP, J.-G. Pariat, SDAVO). longitudinal de la pièce. On remarquera également la présence de quelques dépressions non linéaires, des excoriations assez superficielles.

Cette usure est très localisée et malgré son contour dégressif, on retrouve assez rapidement des traces techniques profondes et visibles à l'oeil nu, tout au moins sur $60 \mathrm{~mm}$ de long. Passée cette partie mésiale, les stigmates de fabrication s'estompent au profit d'une surface aux élévations aplanies, lisse et très brillantes, les dépressions restant ternes et d'aspect rugueux (fig. $5, \mathrm{n}^{\circ} 2$ ).

La signature tracéologique de la partie distale est très comparable à celle que l'on retrouve sur les poinçons utilisés expérimentalement pour perforer de la peau sèche, un matériau à la fois souple et abrasif (Maigrot, 2003). L'étendue de l'usure qui ne s'étend pas à plus de $1 \mathrm{~cm}$ de la partie distale, marque la course de l'outil.

Ce type de poinçon conçu à partir de métapode de cerf est connu dès la fin du Néolithique ancien dans la vallée de la Marne, quelques exemplaires ont notamment été recensés à Jablines (Maigrot en cours). Sa fréquence augmente de manière significative à partir du Néolithique Moyen I et II, tant en contexte d'habitat que funéraire et sur un territoire qui dépasse largement le Bassin parisien. En effet, ces pointes sont courantes dans les assemblages Cortaillod et Néolithique Moyen Bourguignon (Maigrot, 2009). 
Le poinçon a été retrouvé proche d'un amas de produits lithiques, près de la tête de l'individu $\mathrm{B}$; la pointe orientée vers l'est. La position de cet ensemble, bien qu'il n'y ait aucun lien fonctionnel évident de prime abord entre l'élément osseux et les éclats de silex, montre qu'il appartient à l'équipement de l'inhumé.

Les éléments en bois de cerf, peu ou pas transformés sont toujours délicats à interpréter (dépôt ? stock de matière première ? déchet de fabrication ? outil ?). C'est le cas pour la pièce associée à la sépulture $\mathrm{n}^{\circ} 5$ (fig. $4, \mathrm{n}^{\circ} 2$ ). Il s'agit d'une ramure de massacre gauche, quasi complète, appartenant à un adulte. Elle est composée de la calotte crânienne, de la cheville osseuse, de la meule (71 mm x $61 \mathrm{~mm})$, de l'andouiller basilaire (section $=36 \mathrm{~mm} \times 26 \mathrm{~mm}$ ), de l'appendice d'un andouiller de glace, du merrain A (section $42 \mathrm{~mm}$ x $40 \mathrm{~mm}$ ) et de la jonction avec l'andouiller central qui a été fracturé, tout comme l'extrémité proximale du merrain $\mathrm{B}$. L'ensemble mesure près de $50 \mathrm{~cm}$ de longueur. La surface du bois est relativement érodée ce qui nuit à la lecture des traces techniques et fonctionnelles. À l'exception de la fracturation de l'andouiller central et du merrain B, aucune trace technique n'apparaît clairement si ce n'est peut être le début d'un rainurage sur la partie distale du merrain A, face externe.

L'andouiller basilaire est considérablement écourté. Son extrémité présente un important émoussé arrondi symétrique de la corticale jusqu'à apparition de la spongiosa. Ce type d'altération n'a rien de naturel. Les endommagements recensés sur les andouillers basilaires directement rattachés à l'activité du cerf, c'est-à-dire survenus du vivant de l'animal, sont de très légers émoussés asymétriques parfois accompagnés d'enlèvements orientés vers la courbure interne, ce qui n'est pas le cas ici. On note également une légère érosion de la perlure sur la courbure externe de l'andouiller de la ramure de Changis, qui se prolonge jusqu'aux pans de fracture de la calotte crânienne face frontale uniquement. La localisation, la distribution et le type de déformation plaident donc en faveur d'une origine anthropique. Par ailleurs, quelques spots polis ont été repérés sur la surface de la courbure externe de l'andouiller. Malheureusement, la conservation de la pièce n'est pas suffisante pour une analyse microscopique. Un deuxième indice, permet de classer ce bois dans la catégorie « outillage ». Un émoussé de la perlure est visible sur la partie mésiale du merrain A sur toute sa circonférence. Des émoussés de perlure peuvent également apparaître du vivant de l'animal mais ils sont toujours circonscrits aux faces internes. Ils ne peuvent non plus être d'origine taphonomique puisque dans ce cas là ils affecteraient l'intégralité de la ramure. Ils sont donc probablement le résultat d'une activité anthropique. Lors d'un creusement expérimental d'un puits d'extraction de silex, des pics en bois de cerf avaient été utilisés et leurs usures analysées (Bostyn et al., 2005). Si elles ne sont pas strictement comparables, la signature tracéologique des outils expérimentaux et celle de la ramure de Changis présentent de nombreux points communs : localisation et distribution des émoussés des andouillers basilaires (partie active) et du merrain A (zone de préhension). Il pourrait donc s'agir de la même catégorie d'outil (pic utilisé sur des matières minérales) dont le mode de fonctionnement serait légèrement différent.

Les pics en bois de cerf, s'ils sont présents dans les contextes miniers, se font plus rares dans les habitats pour le Néolithique moyen, voire inexistants en particulier pour le Néolithique Moyen Bourguignon.

Le bois de Changis a été retrouvé, fracturé en deux, à l'extrémité sud-ouest de la sépulture, la meule vers l'intérieur et le merrain A vers la paroi du coffre. Sa position stratigraphique montre, d'autre part qu'il était disposé au-dessus du coffre (Pariat, 2007a). Reste à savoir s'il a été déposé directement sur le coffre ou s'il provenait de plus haut (tumulus ?) avant d'avoir basculé suite à l'érosion. S'il avait été déposé à l'air libre, il aurait très probablement fait le bonheur d'une faune très friande de cette matière première riche en sels minéraux. Aussi, l'absence de traces de rongeurs semble davantage plaider en faveur du premier scénario.

Les deux pièces en matières dures animales associées à la sépulture $\mathrm{n}^{\circ} 5$ de Changis Les Pétreaux renvoient à des fonctions différentes, tout au moins dans leur implication respective dans la gestuelle funéraire. Ainsi, la pointe sur métapode de cerf, à l'instar des éclats de silex, sont directement associés à l'équipement personnel de l'individu B. En revanche, le pic en bois de cerf qui a probablement participé à l'inhumation (creusement ? ouverture ou fermeture du coffre ?) semble d'avantage accompagner l'ensemble sépulcral.

\section{SÉPULTURE 11 (STRUCTURE 2370)}

\section{LA FOSSE ET SON COMBLEMENT}

La sépulture 11, qui se trouvait vers l'ouest au pied de la butte, était particulièrement arasée. Les contours très irréguliers d'une hypothétique fosse se démarquaient de la grave sur quelques centimètres d'épaisseur. En effet le remplissage de la tombe se caractérisait par un limon grossier brun qui se détachait assez nettement du substrat.

\section{L'INHUMÉ}

Deux restes humains, des fragments de tibia, appartenant à un même individu provenaient de cette structure. Aucune certitude n'existe mais la face d'apparition et l'orientation de chaque tibia peuvent donner quelques indices sur l'emplacement approximatif de la tête du sujet, à condition que les deux restes soient en place. Les diaphyses apparaissaient en face antérieure et la partie distale était orientée vers le sud-ouest. La moitié supérieure de l'individu se trouvait donc peut-être au nord, les pieds étant au sud (fig. 6).

Il s'agit d'un individu adulte gracile, dont le sexe ne peut pas être déterminé du fait de la mauvaise conservation des restes.

\section{MOBILIER}

Plusieurs vestiges ont été retrouvés à proximité des restes humains. Un bloc de grès se trouvait à $5 \mathrm{~cm}$ au nord-ouest du tibia gauche. Trois blocs de craie furent repérés à quelques centimètres au sud du tibia droit. Un autre bloc de calcaire graveleux pulvérulent se trouvait à l'ouest de l'ensemble osseux. Enfin quatre rognons de silex étaient à $20 \mathrm{~cm}$ au nord-est du tibia droit. 


\section{SÉPULTURE 14 (STRUCTURE 2711)}

\section{LA FOSSE ET SON COMBLEMENT}

La sépulture 14 se trouvait vers l'ouest, au pied de la butte à $50 \mathrm{~m}$ à l'est de la tombe 11. La fosse, localisée dans une zone à forte densité de structures, n'apparaissait pas lors du décapage car elle se trouvait partiellement recoupée par une structure protohistorique. C'est en cherchant les limites de celle-ci que fut mis au jour un crâne humain. En surface, la fosse était tapissée d'un amas de blocs calcaires et de grès pulvérulent, très partiellement étalés par les labours contemporains.

La fosse sépulcrale était ovale mesurant 1,20 m de long pour $0,80 \mathrm{~m}$ de large par $0,40 \mathrm{~m}$ de profondeur. Son profil était à parois sub-verticales et à fond irrégulier. Son comblement limoneux brun foncé hétérogène se démarquait du sédiment encaissant. Plusieurs plaquettes calcaires étaient fichées verticalement jusqu'au fond de fosse.

\section{L'INHUMÉ}

Le seul squelette exhumé reposait en position fléchie sur le côté gauche avec la tête à l'est-nord-est dans l'axe de la fosse (fig. 7). L'angle de flexion du membre supérieur droit était légèrement supérieur à $90^{\circ}$, tandis que celui du gauche était de $120^{\circ}$. Enfin les membres inférieurs étaient hyperfléchis.

Le sujet inhumé était un jeune adulte féminin âgé de 20 à 25 ans.

Dans l'ensemble l'état des surfaces osseuses était satisfaisant, exception faite de quelques enlèvements repérés sur certains os longs. Le tissu spongieux était présent.

La représentation squelettique était correcte. Les os de la tête osseuse étaient au complet. La cage thoracique n'était amputée que de deux vertèbres lombaires. La ceinture des membres supérieurs était intégralement représentée. Quant aux membres supérieurs et inférieurs, les seuls manques observés affectaient les os des extrémités.

\section{Connexions et dislocations}

La tête osseuse était en place laissant apparaître le bloc crânio-facial par sa face latérale droite et la mandibule était en connexion stricte.

Les vertèbres cervicales étaient en connexion, en face latérale droite, de même que les vertèbres thoraciques. Au niveau de l'étage lombaire, les vertèbres présentes formaient un bloc apparaissant en face antéro-inférieure déconnecté du sacrum. Le gril costal droit avait subi un affaissement assez progressif tandis que le gauche était en place.

À droite comme à gauche l'articulation de l'épaule était distendue, les clavicules s'étant déplacées sans que la connexion scapulo-humérale soit affectée. À droite la scapula demeurait d'ailleurs sur chant, en déséquilibre. Au niveau des membres supérieurs, l'articulation du coude droit était distendue et seuls les petits os des mains paraissaient remaniés.

La ceinture des membres inférieurs n'avait pas subi d'ouverture significative. Les articulations des hanches étaient d'ailleurs préservées, tout comme celle des genoux. Chaque patella était en place en équilibre instable. Les os des jambes demeuraient en connexion, la fibula droite apparaissant en déséquilibre. L'articulation de chaque cheville était maintenue, et les métatarsiens à leur place. Les phalanges étaient remaniées.

\section{MiLieu de DéCOMPOSItION ET tYPe DE STRUCtURE}

Cette fosse a accueilli une inhumation individuelle primaire, comme le montre la bonne représentation squelettique et les nombreuses connexions préservées.

Le diagnostic quant au milieu de décomposition s'avère épineux. Les connexions et les situations d'équilibre instable suggérant un espace colmaté abondent (scapula droite, patellas, fibula droite). Paradoxalement, certains os ont subi de légers remaniements tels le coude droit, le gril costal droit ou bien encore la disjonction atypique au niveau du rachis lombaire et du sacrum.

Cette dernière dislocation n'est ni le fait d'une manipulation anthropique préalable à l'ensevelissement ni la conséquence du passage d'un terrier. Nous peinons à l'interpréter, sauf peut-être à envisager l'expression du poids et de la décomposition d'un dépôt périssable, installé sur et sous l'abdomen du défunt.

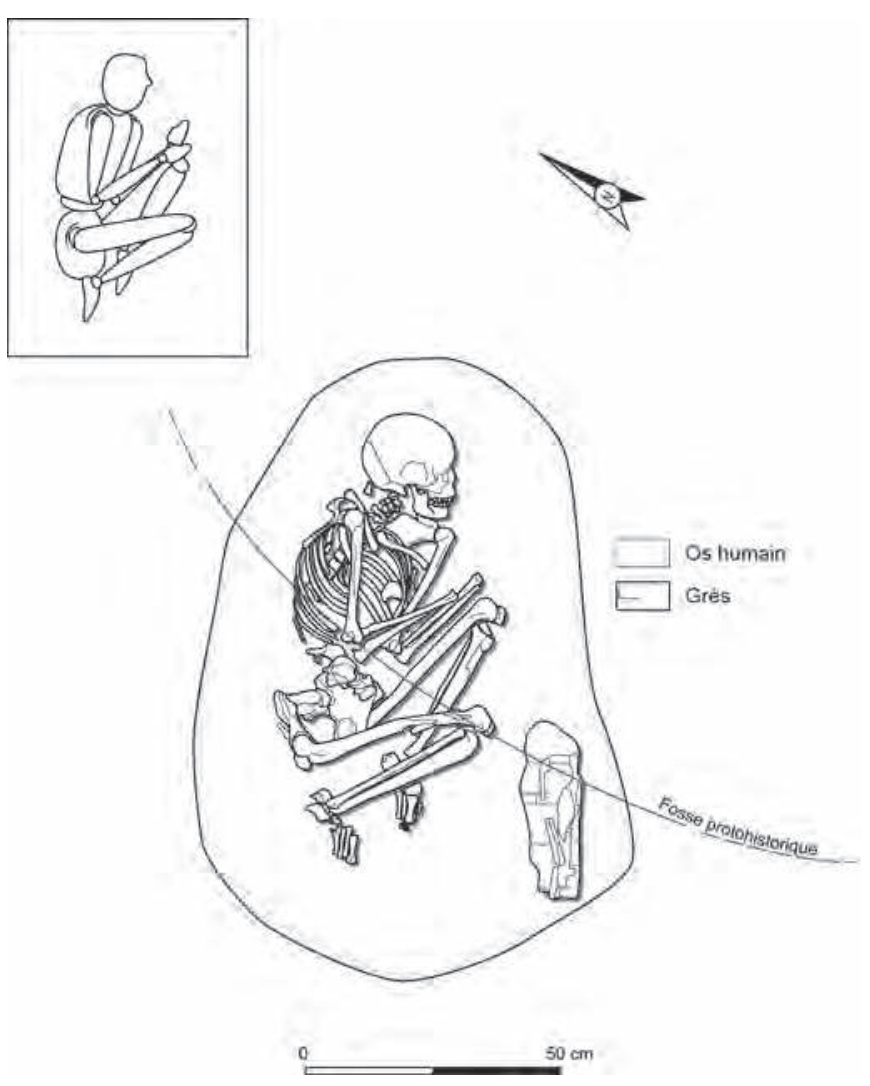

Fig. 7 - Changis-sur-Marne Les Pétreaux, Le Dessus de la Chaussée, plan de la sépulture 14 (DAO : C. Thevenet, INRAP).

Changis-sur-Marne Les Pétreaux, Le Dessus de la Chaussée, plan of Burial 14 (graphics: C. Thevenet, INRAP). 


\section{LE MOBILIER}

L'unique vestige mobilier est un grattoir sur lame en silex tertiaire bartonien issu du remplissage supérieur. Ce type de silex est présent sous forme de plaquette à l'état naturel dans l'environnement local du site (Lanchon et al., 2008). L'objet présente une retouche en partie distale. Sa présence dans le remplissage de la tombe est résiduelle, puisque d'autres pièces du même type proviennent de l'occupation du Néolithique ancien toute proche.

\section{SÉPULTURE 18 (STRUCTURE 4141)}

\section{LA FOSSE ET SON COMBLEMENT}

La sépulture 18 se trouvait à mi-pente dans la partie médiane de l'emprise. La fosse sépulcrale affleurant sous la terre végétale se démarquait nettement du sédiment encaissant. Elle mesurait $1 \mathrm{~m}$ de long par 0,87 $\mathrm{m}$ de large pour 0,42 $\mathrm{m}$ de profondeur. De forme quadrangulaire, cette fosse présentait des parois obliques et un fond arrondi. Son comblement limoneux brun foncé se démarquait du sédiment encaissant (fig. 8).

Enfin plusieurs blocs de grès se trouvaient contre le flanc sud-ouest de la fosse, et deux autres apparaissaient sur le fond entre les défunts.

\section{LES INHUMÉS}

Deux squelettes occupaient la moitié nord-est de la fosse. Le sujet $\mathrm{A}$, à l'est, reposait en position repliée sur le côté gauche avec la tête orientée vers le nord-ouest. Le sujet B, immédiatement à l'ouest du sujet $\mathrm{A}$, reposait sur côté gauche avec la tête au nord-ouest. Le genou gauche de cet individu était au contact de l'os coxal droit du sujet A.

Le membre supérieur droit du sujet A était fléchi à $90^{\circ}$ tandis que le membre gauche était hyperfléchi, la main se retrouvant au niveau de l'épaule. Les membres inférieurs étaient également très fléchis, et remontés vers le thorax. Quant à l'individu B, les membres supérieurs et inférieurs étaient hyperfléchis.

Ces deux sujets étaient de jeunes adultes, l'individu A étant de sexe féminin et le sujet B étant de sexe indéterminé.

Dans l'ensemble les surfaces osseuses étaient altérées et quelques ossements du sujet A furent perturbés par les engins mécanique lors du décapage. Par contre, le tissu spongieux était présent dans les diaphyses des os longs.

Exception faite des membres inférieurs, le squelette du sujet A était complet, comparativement au sujet B dont il subsistait peu d'éléments du tronc et des grils costaux. De nombreux os manquaient également au niveau des ceintures des membres et des extrémités.

Ces déficits assez importants s'expliquent par une érosion accrue dans cette partie du site.

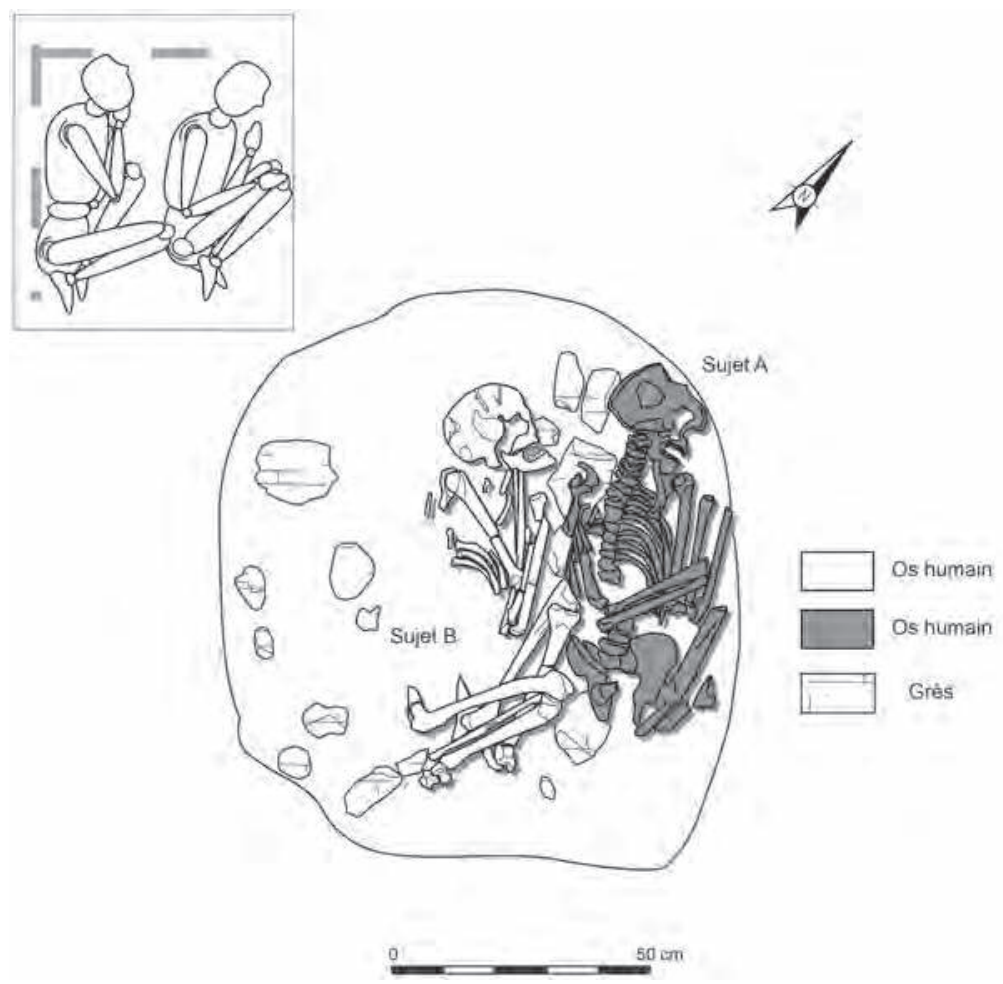

Fig. 8 - Changis-sur-Marne Les Pétreaux, Le Dessus de la Chaussée, plan de la sépulture 18 (DAO : V. Delattre, INRAP, J.-G. Pariat, SDAVO).

Changis-sur-Marne Les Pétreaux, Le Dessus de la Chaussée, plan of Burial 18 (graphics: V. Delattre, INRAP, J.-G. Pariat, SDAVO). 


\section{CONNEXIONS ET DISLOCATIONS}

Le bloc crânio-facial de l'individu A apparaissait par sa face latérale droite, avec le front orienté vers le nord-est. La mandibule, également en face latérale droite, était en connexion avec le crâne.

Les vertèbres cervicales étaient en connexion stricte en face antérieure, ainsi que les vertèbres thoraciques et lombaires. Les côtes droites étaient en connexion lâche laissant apparaître leur face externe et supérieure. À gauche le gril costal avait subi une mise à plat, les côtes apparaissant par leur face interne.

L'articulation de l'épaule droite n'était pas observable du fait de dégradations survenues lors du décapage. La scapula reposait sur une pierre, en face antéro-latérale. Seule la moitié distale de l'humérus apparaissait en face latérale dans une position cohérente par rapport à celle de la scapula. L'articulation du coude était distendue, et les os des avant-bras se trouvaient en face postérieure.

Du côté gauche la clavicule était verticalisée et l'articulation scapulo-humérale était préservée. L'humérus était en face antérieure et le coude était en connexion lâche, l'ulna apparaissait en face médiale, et le radius en face antéro-médiale, immédiatement à l'est.

Le volume du bassin était partiellement préservé. L'os coxal droit recouvrait en partie le sacrum, dégageant ainsi sa face latérale. Seule la tête du fémur était encore en place dans l'acétabulum. À gauche, l'os coxal était à plat, en face médiale et l'articulation de la hanche était maintenue. Le fémur apparaissait en face postérieure et les fragments encore en place du tibia et de la fibula étaient immédiatement à l'est, de telle sorte que le talon gauche se retrouve contre l'os coxal gauche et que le genou soit remonté vers le haut du corps.

La tête osseuse de l'individu B était en place. Le bloc crâniofacial apparaissait en face latérale droite, et la mandibule était en connexion avec le crâne, également en face latérale droite.

Les trois premières vertèbres cervicales étaient en connexion et apparaissaient en face latérale droite. Les seules côtes gauches conservées apparaissaient en face interne suggérant une mise à plat du gril costal.

L'articulation de l'épaule droite était préservée, la scapula apparaissant en face latérale et l'humérus en face postéro-latérale. L'articulation du coude était distendue et la partie distale des os de l'avant-bras se trouvait sous le menton.

L'épaule gauche était en connexion sous l'avant-bras gauche. L'humérus était d'ailleurs dans une position inhabituelle, puisqu'il se trouvait en face latérale, là où il aurait dû être en face médiale, position trahissant vraisemblablement une contrainte. Le coude était en connexion, radius et ulna se retrouvant au sud-ouest de l'humérus dans une position fortement contrainte.

Malgré l'érosion, l'articulation de la hanche droite était préservée. Le fémur se trouvait en face latérale et le tibia était en connexion avec ce dernier, également en face latérale ; la fibula avait basculé en arrière du tibia. Les seuls os du tarse conservés, le talus et le calcanéus, étaient en connexion lâche. Du côté gauche, l'articulation de la hanche était maintenue et le fémur se trouvait en face postéro-médiale. Le tibia, en connexion lâche, apparaissait par sa face antérieure et la fibula se trouvait sous celui-ci. Enfin talus et calcanéus étaient en place en face médiale, légèrement supérieure.

\section{MiLIEU DE DÉCOMPOSITION ET TYPE DE STRUCTURE}

Dans les deux cas, la représentation squelettique est relativement équilibrée en dépit des déficits observés, et la cohérence anatomique est bonne ce qui implique des inhumations primaires.

La fosse sépulcrale ne présentait pas de recoupement pouvant suggérer un dépôt différé du second corps. Par ailleurs, le genou droit de l'individu B était en contact avec le bassin de l'individu A. Par conséquent l'homogénéité du comblement et le contact immédiat entre les deux squelettes permettent d'affirmer qu'il s'agit d'une sépulture double impliquant le dépôt simultané de deux corps.

La restitution du milieu de décomposition des cadavres n'est pas aisée, tant l'érosion est intense. On observe une moindre migration des os et l'absence de désarticulation majeure. L'équilibre instable de l'humérus et de la scapula droits du sujet B suggèrent soit un comblement rapide, soit un colmatage différé. Ce dernier pourrait résulter de la présence d'une enveloppe souple et rigide autour du corps, dispositif qui expliquerait d'ailleurs les fortes contraintes observées par exemple au niveau du membre supérieur gauche du sujet B.

Outre cet hypothétique enveloppement du corps, on pourra s'interroger sur la présence éventuelle d'un dispositif funéraire. En effet l'espace de la fosse est surdimensionné par rapport à l'espace occupé par les squelettes. Des pierres alignées ont été mises au jour entre les deux dépouilles et à leur contact matérialisant une éventuelle séparation. Au même titre, les blocs de pierre retrouvés contre le flanc sud-ouest de la fosse pourraient correspondre à des éléments de calage d'une superstructure. Toutefois nous peinons à restituer ce dispositif, car l'espace reste très nettement insuffisant au sud pour pouvoir envisager la présence d'une cloison entre l'avant-bras gauche du sujet A et la paroi de la fosse d'implantation.

\section{SÉPULTURE 19 (STRUCTURE 5689)}

\section{LA FOSSE ET SON COMBLEMENT}

La sépulture 19 se trouvait dans la moitié sud de l'emprise de la fouille à mi-pente. En surface, une imposante dalle de grès de forme triangulaire, mesurant $1,50 \mathrm{~m}$ de long pour $90 \mathrm{~cm}$ de large, recouvrait partiellement une fosse au contour peu lisible de 1,90 $\mathrm{m}$ de long par 1,50 $\mathrm{m}$ de large, et conservée sur une épaisseur de $30 \mathrm{~cm}$ (fig. 9). Une couche limoneuse allant du brun rouge au brun foncé d'une dizaine de centimètres d'épaisseur séparait la dalle des squelettes humains.

\section{LES INHUMÉS}

Outre un fragment d'arc postérieur de vertèbre thoracique immature provenant de la couche limoneuse interstitielle, deux squelettes furent mis au jour dans une fosse subcirculaire à parois obliques et au comblement limoneux brun organique de la fosse. Ils étaient disposés tête bêche (fig. 10). 

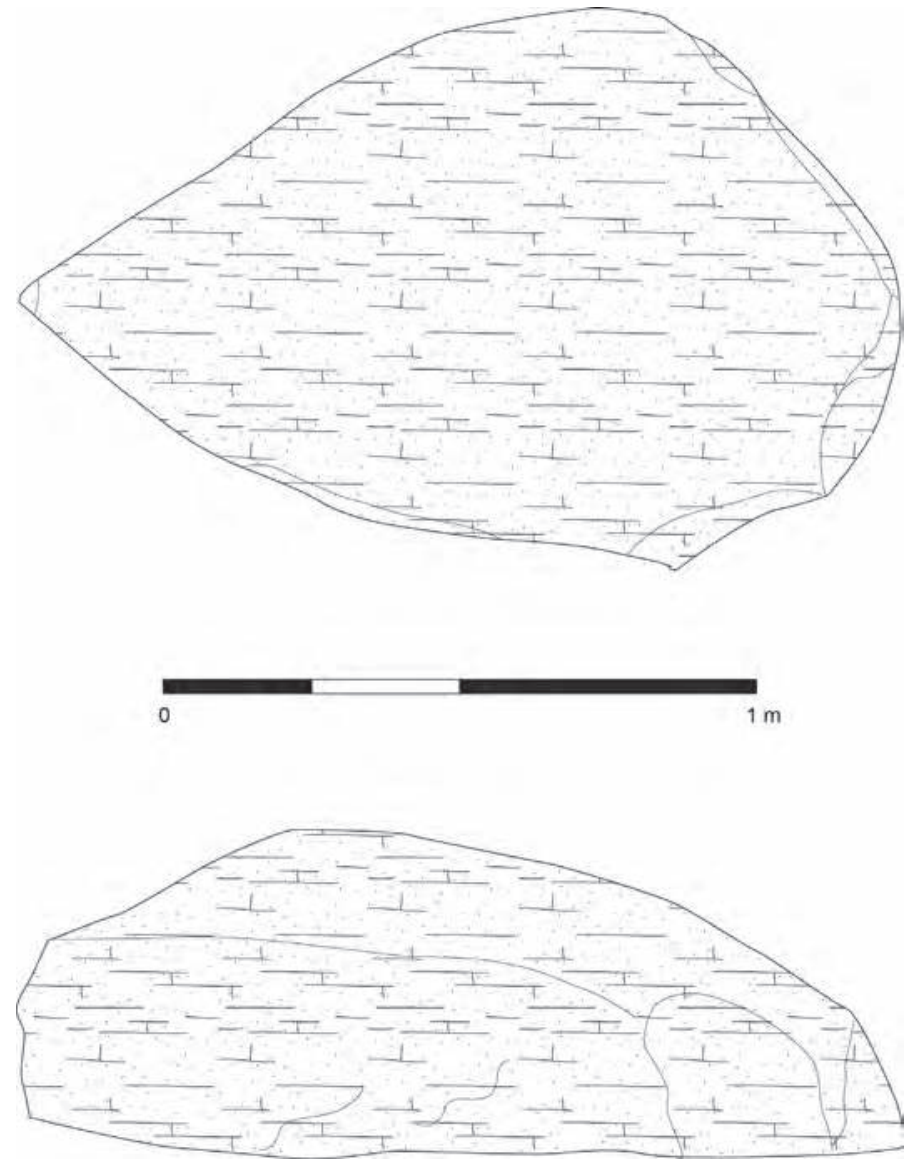

Fig. 9 - Changis-sur-Marne Les Pétreaux, Le Dessus de la Chaussée, plan de la dalle de grès recouvrant la sépulture 19 (DAO : J.-G. Pariat, SDAVO).

Changis-sur-Marne Les Pétreaux, Le Dessus de la Chaussée, plan of the sandstone slab covering Burial 19 (graphics: J.-G. Pariat, SDAVO).

Le sujet A, au nord, était orienté nord-ouest / sud-est, la tête au nord-ouest. Le sujet B, au sud, était orienté est / ouest, la tête à l'est.

L'individu A était replié sur le côté gauche. Les os de l'avant-bras droit étaient ramenés vers le bras en avant de la cage thoracique formant un angle de $45^{\circ}$. La position de l'humérus gauche indiquait un déplacement du sud-ouest vers le nord-est mais sa partie distale était restée en connexion avec l'ulna. On peut en conséquence supposer que le degré de flexion entre les os du bras et de l'avant-bras gauche était comparable à celui du membre supérieur droit. Les membres inférieurs étaient tous deux fléchis à $60^{\circ}$.

La position du sujet $\mathrm{B}$ était lisible, malgré des remaniements occasionnés par le retrait mécanique de la dalle de grès. Il était fléchi sur le côté droit. La position des membres supérieurs n'était pas observable. On peut cependant supposer qu'ils occupaient une position proche de celle de l'individu A. Les membres inférieurs, bien que perturbés étaient fléchis à $45^{\circ}$.

Le sujet $\mathrm{A}$ se situait à une dizaine de centimètres au-dessous du sujet B, au nord. Seul le genou droit de l'individu B reposait au-dessus des vertèbres lombaires de l'individu A.
L'individu A était un adulte de sexe masculin. Aucune estimation d'âge n'a été tentée, vu la forte fragmentation. Le sexe du sujet B était indéterminé en raison de la fragmentation trop importante des os coxaux.

L'os était globalement en bon état. Les épiphyses et les diaphyses étaient entières, la corticale était présente et mis à part la diaphyse du radius gauche du sujet $\mathrm{B}$, aucun os ne comportait des traces de dents ou de griffes.

En dehors du crâne, les restes humains de l'individu A étaient nombreux et peu fragmentés, quelques déficits affectant pourtant les os des extrémités. Les restes de l'individu B étaient très fragmentés et il manquait plus d'ossements : côtes, quelques vertèbres thoraciques et lombaires, sternum, os des extrémités.

\section{Connexions et disLOCATIONS}

Le sujet A était en connexion. Les os du bloc crânio-facial étaient dispersés sur environ $40 \mathrm{~cm}$ mais leur position relative par rapport aux vertèbres cervicales demeurait logique. Un alignement de grès perpendiculaire à l'axe du crâne apparaissait sur un axe nord-est / sud-ouest.

La cage thoracique avait perdu son volume initial. La colonne vertébrale était en connexion partielle. Ainsi, l'étage cervical n'était pas en connexion avec le reste de la colonne vertébrale. Il était décalé d'une dizaine de centimètres au nordouest des vertèbres thoraciques. Toutes les vertèbres apparaissaient en face postérieure légèrement latérale. Les côtes droites s'étaient effondrées et apparaissaient, pour la plupart, en face supérieure. Les côtes gauches étaient en place.

Les os de la ceinture du membre supérieur étaient déconnectés et la clavicule droite apparaissait en face antérieure, l'extrémité acromiale orientée vers le sud ce qui indiquait un déplacement. Les os du membre supérieur droit avaient subi de faibles remaniements. L'humérus droit apparaissait en face latérale légèrement postérieure mais il était en connexion avec les os de l'avant-bras. Des bouleversements plus importants affectaient le membre supérieur gauche. Le quart distal de la diaphyse humérale était en face postérieure et recouvrait la partie proximale des os de l'avant-bras.

Les os de la ceinture du membre inférieur étaient déconnectés. Le sacrum apparaissait en face postérieure de même que l'os coxal droit. L'os coxal gauche était resté en place et apparaissait par sa face médiale. La tête du fémur droit n'était pas en connexion dans l'acétabulum de l'os coxal. Le lien anatomique était légèrement distendu. La partie proximale du fémur droit avait basculé en face antérieure légèrement latérale. Le fémur gauche apparaissait en face médiale et se trouvait dans une position proche de celle qu'il devait avoir à l'origine. Aucun des fémurs n'était en connexion stricte avec les os de la jambe. Le tibia droit apparaissait en face latérale sous la fibula droite, qui apparaissait elle-même en face latérale. Le tibia gauche apparaissait en face médiale à quelques centimètres au nord-est de la fibula gauche. Enfin, les os de la cheville étaient en connexion. Les os du pied droit étaient en place, contrairement à ceux du pied gauche qui étaient disloqués.

L'individu B, particulièrement fragmenté, était en connexion partielle. Aucun os ne fut retrouvé au-delà d'un axe est-ouest, jouxtant le squelette au sud. Le crâne apparaissait en face 

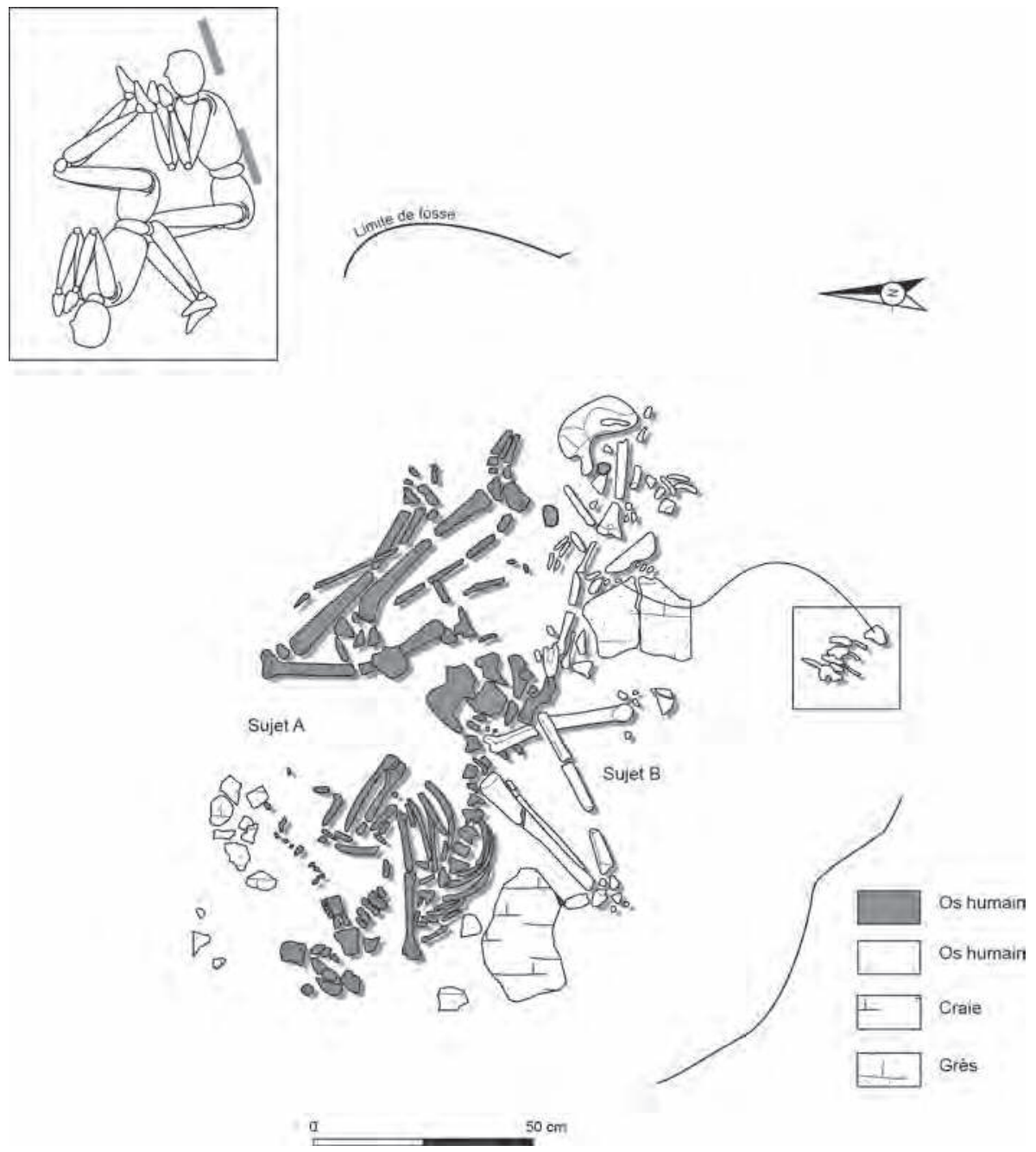

Fig. 10 - Changis-sur-Marne Les Pétreaux, Le Dessus de la Chaussée, plan de la sépulture 19 (DAO : J.-G. Pariat, SDAVO).

Changis-sur-Marne Les Pétreaux, Le Dessus de la Chaussée, plan of Burial 19 (graphics: J.-G. Pariat, SDAVO).

latérale, la partie supérieure orientée vers l'est. Il était en connexion avec la mandibule.

La partie supérieure gauche du squelette a souffert du retrait de la dalle entraînant le déplacement des os de la ceinture et du membre supérieur. Ainsi l'humérus gauche était remonté à hauteur du crâne et se trouvait déconnecté des os de l'avant-bras. L'humérus droit apparaissait, quand à lui, en face antérieure le long de l'axe de la colonne vertébrale. Les os de l'avant-bras étaient sans doute faiblement repliés sur le bras mais la forte fragmentation a rendu difficile leur détermination. Les mains étaient ramenées en avant de la cage thoracique.

La plupart des os du squelette appendiculaire étaient recouverts par un bloc de pierre de $25 \mathrm{~cm}$ de long sur $15 \mathrm{~cm}$ de large sans doute à l'origine de la fragmentation des ossements retrouvés dans cette zone. L'étage cervical était dans l'ensemble en connexion. Les étages thoraciques et lombaires étaient mal conservés et déconnectés. Les fragments de côtes étaient peu nombreux.

Les os de la ceinture du membre inférieur avaient également subi d'importants déplacements du sud vers le nord. Le fémur droit n'était pas en place. Son déplacement d'est en ouest avait vraisemblablement engendré la rupture des connexions avec le bassin dans sa partie proximale et avec la jambe dans sa partie distale. Les remaniements étaient plus faibles au niveau des os des jambes. Le tibia et la fibula droits étaient dans une position proche de celle d'origine, et le tibia gauche se trouvait anormalement au-dessus de la fibula gauche. Enfin, les os du tarse droit étaient déconnectés et fragmentés tandis qu'il n'y avait aucun reste pour le tarse gauche.

\section{Milieu de décomposition et type De structure}

Plusieurs arguments permettent d'affirmer que la décomposition s'est faite sur place. Tout d'abord les deux sujets présentent des connexions strictes et la logique anatomique est respectée lorsque les liens sont distendus. Les dents, souvent présentes sur le lieu de décomposition, sont nombreuses. Les quelques déficits constatés au niveau des os des extrémités peuvent être expliqués par l'action des animaux fouisseurs.

L'agencement des deux sujets permet d'affirmer que l'individu A a été déposé avant l'individu B. Ce dernier repose en effet à une profondeur moindre que dans le cas du sujet A. Quel est cependant l'intervalle de temps qui s'est écoulé entre chaque inhumation? Les deux sujets sont séparés par une faible quantité 
de sédiment. Il est donc possible que ces deux inhumations soient contemporaines. En effet quelques jours ont pu séparer ces deux dépôts primaires. Aucune trace d'intervention ultérieure n'a pu être mise en évidence. La plupart des bouleversements survenus s'explique logiquement par la pression exercée par le poids de la dalle de couverture, les dommages liés au retrait mécanique de la dalle, et les perturbations d'origine animale.

La décomposition s'est déroulée au sein d'un espace vide pour le sujet A comme pour le sujet B. Ainsi les os du sujet A ont été mobilisés au sein de l'espace sépulcral, à l'instar de la cage thoracique effondrée, de la hanche droite disloquée ou bien encore du pied gauche, déconnecté.

Il est plus délicat de caractériser le dispositif qui garantissait un tel espace tant les indices sont ténus. S'il ne fait aucun doute qu'il s'agissait d'un contenant périssable, il est en revanche impossible d'en cerner les limites ; sauf peut-être au sud, car aucun ossement du sujet B n'a été retrouvé dans cette zone. On peut donc envisager la présence d'une paroi rectiligne à cet endroit. Les blocs de pierre alignés au niveau de la tête de l'individu A appartiennent peut-être aussi au dispositif de protection des corps.

Il reste enfin à revenir sur les causes possibles de la présence de l'os immature identifié parmi les os bougés. Celui-ci a pu appartenir à un sujet inhumé au-dessus de la sépulture 19, les labours répétés au fil des siècles engendrant la destruction d'une partie des restes et la dispersion de l'autre partie. Cette hypothèse est peu recevable étant donné la présence de la dalle de grès empêchant toute pénétration, par le haut, d'os dans la sépulture 19. Il se peut en revanche que cet os, du fait de sa petite taille, ait été transporté par un animal fouisseur. Ceci permet d'envisager la présence à proximité de la tombe 19 d'une sépulture renfermant au moins un sujet immature, éventuellement détruite.

\section{SÉPULTURE 20 (STRUCTURE 5695)}

\section{LA FOSSE ET SON COMBLEMENT}

La sépulture 20 se trouvait à quelques mètres au sud-est de la sépulture 19, à mi-pente. Les restes de deux squelettes humains apparurent dans une fosse au contour ovale de $1,30 \mathrm{~m}$ de long par $0,90 \mathrm{~m}$ de large dont le profil était en cuvette (fig. 11). Le remplissage supérieur était caractérisé par un limon brun rouge sur $15 \mathrm{~cm}$ d'épaisseur. Les ossements se trouvaient dans le comblement inférieur brun sableux avec quelques blocs de pierres, entre 15 et $20 \mathrm{~cm}$ de profondeur. L'un d'eux, un bloc de grès d'une longueur de $35 \mathrm{~cm}$ pour une largeur de $30 \mathrm{~cm}$, fut malencontreusement déplacé sur toute la surface de la fosse du sud-ouest vers le nord-est lors du décapage perturbant partiellement l'un des squelettes.

\section{LES INHUMÉS}

Le sujet $\mathrm{A}$ a fait l'objet d'une réduction de corps. Le crâne était orienté vers le sud-ouest et la plupart des os des pieds étaient au nord-est. Le sujet B était orienté sud-ouest / nord-est, la tête au sud-ouest.
Les restes de l'individu A étaient regroupés dans une même zone à l'est de l'individu $\mathrm{B}$.

Le sujet B était fléchi sur le côté gauche, les membres supérieurs étant repliés à $45^{\circ}$ en avant de la cage thoracique. Les membres inférieurs apparaissaient hypercontractés. Les os de la jambe étaient ramenés vers les cuisses à hauteur des membres supérieurs. Ainsi le genou gauche se trouvait sur la même ligne que la main gauche et les jambes étaient remontées au niveau du bassin.

Les deux sujets reposaient à peu près à la même profondeur.

Le sexe de l'individu A était indéterminé, malgré la bonne conservation des deux-tiers inférieurs de l'os coxal gauche. La surface auriculaire des deux os coxaux était détruite ce qui n'a pas permis de détermination de l'âge de cet individu.

Le sujet $\mathrm{B}$, de sexe indéterminé, était particulièrement gracile. D'après la surface auriculaire, le sujet avait entre 30 et 59 ans.

Les surfaces osseuses étaient conservées et le tissu spongieux était présent. Les diaphyses des os longs étaient dans l'ensemble entières, tandis que les épiphyses étaient fragmentées et incomplètes.

Les restes du sujet $\mathrm{A}$, très fragmentés, étaient inégalement représentés. Les os étaient peu nombreux voire absents, à l'exception des os du crâne et des os longs. Dans le cas du sujet B, d'importants déficits affectaient trois grandes régions anatomiques : la cage thoracique, les extrémités des membres supérieurs et inférieurs.

Plusieurs facteurs peuvent être à l'origine de ces déficits. Des problèmes de conservation dus à la nature acide du sol ont pu conduire à la destruction de certains os, à l'instar des corps vertébraux du sujet B. Les labours répétés au cours du temps ont également pu conduire à la disparition progressive de certains restes. Enfin la fragmentation importante a rendu difficile la détermination de certains vestiges. Certains os manquants se trouvent donc peut-être parmi les restes classés dans la catégorie « Indéterminés ».

\section{Connexions et Dislocations}

Les os du sujet A étaient presque complètement disloqués. Une seule connexion lâche subsistait entre les trois-quarts proximaux de l'ulna gauche et la diaphyse du radius correspondant.

Le crâne était situé en limite de fosse, à l'est. La plupart des os longs se trouvaient à quelques centimètres au nord-est du crâne. Os longs des membres supérieurs et inférieurs étaient totalement mélangés à des fragments de mandibule, d'os coxal, de côtes et à des petits os.

Plusieurs os longs étaient alignés à proximité du bord est de la fosse : un fragment de diaphyse fémorale gauche, un fragment d'épiphyse proximale de fémur gauche et les troisquarts distaux d'une diaphyse humérale. Ces restes, situés à plus de $6 \mathrm{~cm}$ du bord de la fosse, pourraient avoir subi un effet de paroi selon un axe sud-ouest / nord-est.

Le crâne du sujet B était en place, la face orientée vers l'ouest, tandis que la mandibule apparaissait incomplète et déconnectée, au nord du bloc crânio-facial. 


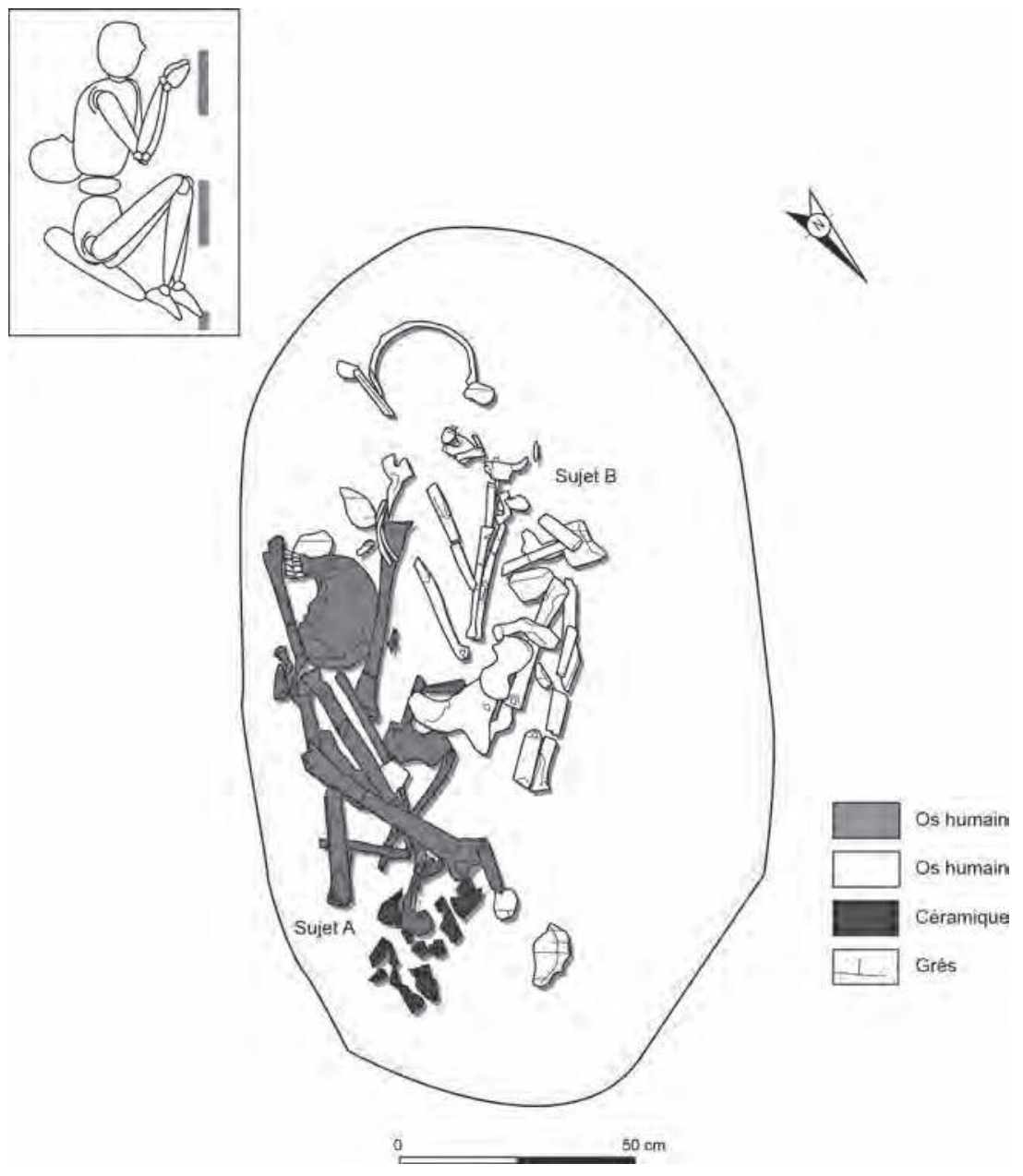

Fig. 11 - Changis-sur-Marne Les Pétreaux, Le Dessus de la Chaussée, plan de la sépulture 20 (DAO : J.-G. Pariat, SDAVO).

Changis-sur-Marne Les Pétreaux, Le Dessus de la Chaussée, plan of Burial 20 (graphics: J.-G. Pariat, SDAVO).

Au niveau du thorax, une seule vertèbre était en connexion avec une côte droite. Le reste de la colonne et les côtes avaient disparu.

Les restes de la ceinture des membres supérieurs n'étaient pas en connexion, malgré une position vraisemblablement proche de celle d'origine. Les membres supérieurs étaient en connexion lâche.

Le bassin n'a pas conservé son volume originel : l'os coxal gauche était à plat et apparaissait en face médiale. L'os coxal droit apparaissait par sa face postérieure. Les quelques fragments de sacrum retrouvés ne permettent pas d'en lire la position. Le fémur gauche était en connexion avec l'os coxal tandis que l'articulation de la hanche droite était disloquée. Les os du genou n'étaient pas en connexion stricte, mais les déplacements étaient de faible ampleur. La fibula droite n'était plus en équilibre sur le tibia droit, mais elle n'outrepassait pas une limite vers le nord-ouest, au-delà de laquelle aucun os n'apparaissait. Les quelques os du tarse (talus, calcanéus) retrouvés avaient subi des déplacements sur une vingtaine de centimètres dans un sens nord-est / sud-ouest et se retrouvaient au niveau du bassin.

\section{Milieu de décomposition et type De structure}

Le sujet B s'est clairement décomposé sur place, car il subsiste des connexions et l'agencement anatomique des restes est cohérent. Concernant le sujet A, les restes sont relativement nombreux et correspondent tant à des grands os qu'à des petits os. Même si les os sont, pour la plupart déconnectés, leur agencement anatomique garde une certaine cohérence qui permet d'envisager le dépôt d'un cadavre complet, dont le squelette fut simplement repoussé après décomposition.

Les deux dépôts effectués dans cette fosse ne sont pas simultanés. Le sujet A déposé dans un premier temps, a fait l'objet d'une réduction avant l'arrivée d'une nouvelle dépouille, en l'occurrence celle de l'individu B. En effet, le squelette du sujet A ne semble guère avoir été l'objet de prélèvements mais bien d'un simple regroupement de restes en limite de fosse, si l'on en juge notamment par la cohérence anatomique préservée.

La durée qui s'est écoulée entre les deux dépôts est complexe à évaluer. Cependant un fragment d'arc postérieur d'atlas retrouvé en position secondaire appartenant au sujet A indique que la première vertèbre cervicale était déconnectée du 
bloc crânio-facial. Par conséquent le cadavre de l'individu A était largement décomposé lors du dépôt du sujet B, puisque l'articulation atlanto-occipitale était rompue.

La nature collective du dépôt implique la présence d'un contenant et donc une décomposition au sein d'un espace vide : les restes du sujet $\mathrm{A}$ ont été réduits à la seule condition qu'il y ait eu de la place disponible dans la sépulture. Les observations réalisées sur le sujet $\mathrm{B}$ confirment l'existence de cet espace vide. La plupart des connexions sont lâches et le volume de certaines parties anatomiques n'est pas maintenu. Par ailleurs les ossements n'ont pas été mobilisés sur des distances conséquentes, en particulier vers le nord-ouest, comme si une paroi les en avait empêché. Outre ces indices, la présence de blocs de pierre constitue un argument supplémentaire en faveur d'un dispositif de calage destiné à un contenant périssable dont il est assez difficile d'imaginer l'aspect. Peut-être s'agissait-il d'un coffre ou d'un coffrage en bois.

\section{LE MOBILIER}

De nombreux tessons appartenant à un seul et même vase furent retrouvés dans la partie est de la fosse, près d'un des fémurs du sujet A et presque contre la paroi de la fosse.

Cette section reprend l'essentiel d'une contribution effectuée par Y. Lanchon dans le cadre du rapport intermédiaire de fouille remis au SRA Ile-de-France en 2002 (Lafage et al., 2002). La sépulture 20 était accompagnée d'un unique vase, qui, de par sa position, constitue clairement un mobilier d'accompagnement funéraire (fig. 12 et 13).
Ce vase, non décoré, est de dimensions modestes (hauteur : $11,6 \mathrm{~cm}$, diamètre à l'ouverture : $8 \mathrm{~cm}$, diamètre maximum : $11,5 \mathrm{~cm}$ ).

La cuisson de la pâte est bonne, la surface externe, de couleur brun-cuir, a été sommairement lissée. La face interne brun foncée à noir a gardé, vers le fond du vase, quelques traces de fabrication. L'argile (fluviatile ?) a été dégraissée à l'aide de nodules de calcaires, mais également de coquilles pilées. La taille du dégraissant dépasse rarement $2 \mathrm{~mm}$, et jamais plus de $5 \mathrm{~mm}$.

Le profil présente un point d'inflexion dans le quart supérieur, ce qui permet d'individualiser un col à bord sub-vertical. Le fond, arrondi, présente un léger aplatissement. Le vase est muni de deux préhensions très particulières, rapportées en symétrie binaire légèrement au dessus du diamètre maximum du vase. Ces préhensions ont une perforation horizontale très régulière de $6 \mathrm{~mm}$ de diamètre, en partie forées dans l'épaisseur de la paroi. Elles sont très larges $(42 \mathrm{~mm})$ et présentent un ensellement médian prononcé. Elles semblent en fait constituées, non d'un ruban ou d'un boudin ensellé, mais plutôt de deux boutons accolés, dont la juxtaposition a provoqué une surépaisseur intermédiaire.

Le type de sépulture et les pratiques funéraires mises en évidence incitent à rechercher d'éventuels indices de datation du vase dans le Néolithique moyen ou au début du Néolithique récent. L'association forme / préhensions / technologie est à notre connaissance inédite dans les corpus céramiques du Bassin parisien ; les rares éléments de comparaison ont été délicats à identifier et ont nécessité des échanges d'informa-

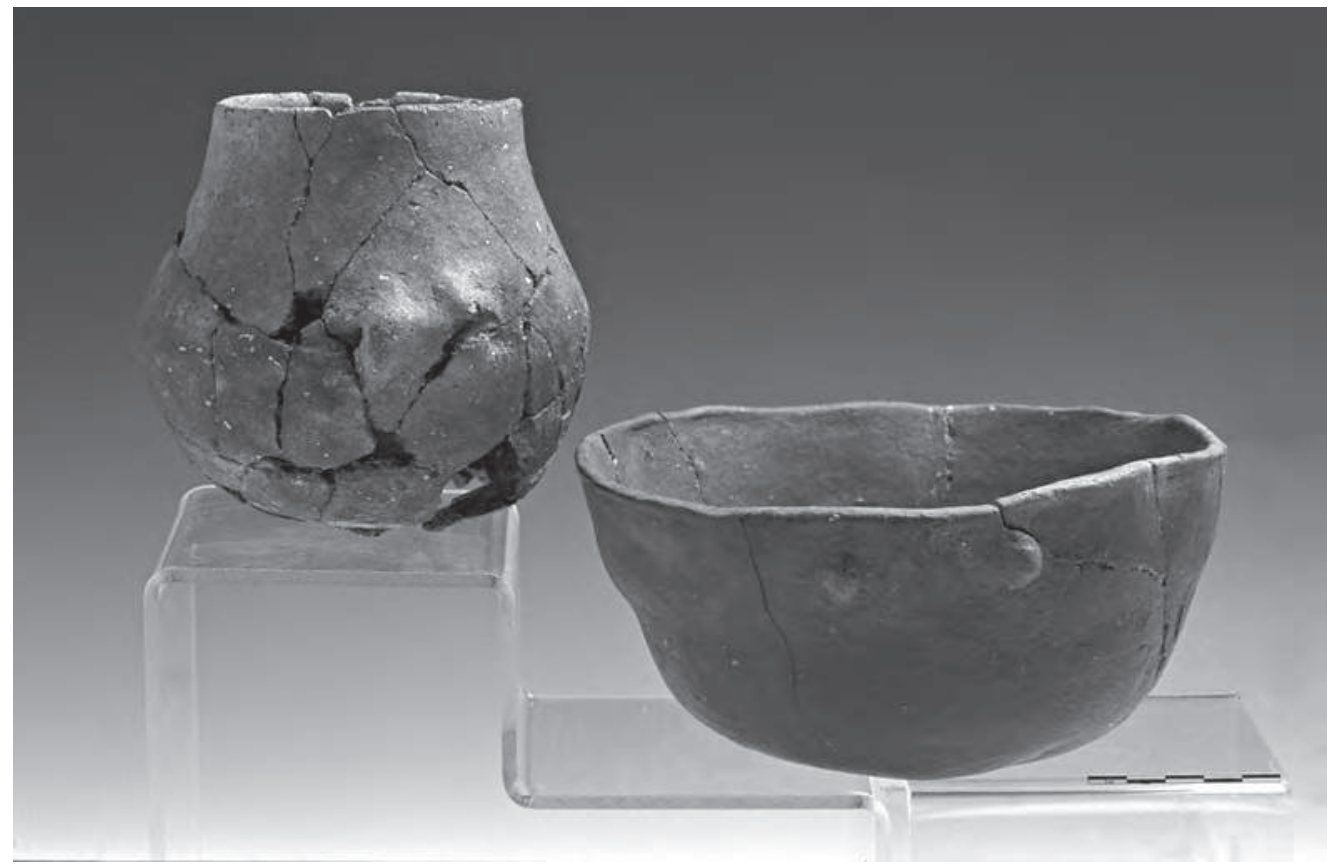

Fig. 12 - Changis-sur-Marne Les Pétreaux, Le Dessus de la Chaussée, vases issus des tombes 20 (à gauche) et 23 (à droite ; cliché : V. Brunet, INRAP).

Changis-sur-Marne Les Pétreaux, Le Dessus de la Chaussée, vessels from Burial 20 (left) and 23 (right; photograph: V. Brunet, INRAP). 


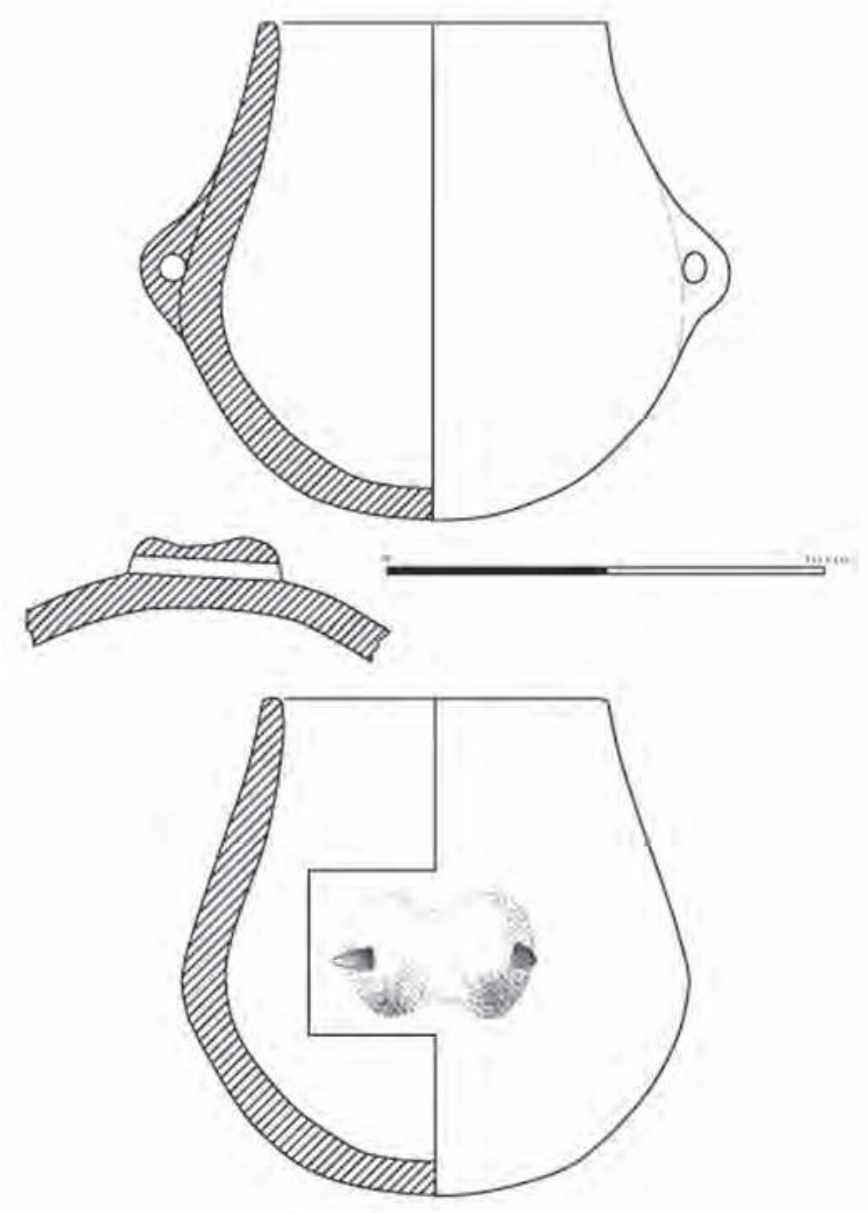

tions avec d'autres chercheurs (P. Chambon, J. Dubouloz, D. Mordant, L. Salanova). Il a fallu en fait analyser et comparer indépendamment chaque élément du vase.

Les préhensions : le type de préhension existe (en symétrie ternaire) en Franche Comté dans le niveau X de la Grotte de Gonvillars (Pétrequin A.M. et P., 1984, fig. $5 \mathrm{n}^{\circ}$ 3) ou sur le camp de la Roche d'Or à Besançon (ibid. fig.11 $\mathrm{n}^{\circ} 4$ ), en contexte Néolithique Moyen Bourguignon. On en trouve également dans le même contexte chrono-culturel au camp de la Vergentière à Cohons (Lepage, 1980, fig. $1 \mathrm{n}^{\circ} 14$ ).

La forme : la forme d'un vase provenant de Noyen type Ft évoque celle du vase de Changis ; les comparaisons s'arrêtent là, puisque tant l'épaisseur, la technologie et surtout les préhensions en «flûte de pan » renvoient le premier vers le Chasséen (type Chassey évolué, Mordant C. et D., 1972).

C'est dans le groupe de Balloy type Gros Bois (Mordant, 1967) qu'on a trouvé les similitudes les plus fortes dans l'épaisseur des parois des vases et surtout dans l'aplatissement des fonds (fig. $2 \mathrm{~B} \mathrm{n}^{\circ} 14$ ). Un vase récemment découvert dans la tombe 135 de Villiers-sur-Seine Le Gros Buisson est morphologiquement très proche de celui de Changis (Meunier in Peake, 2006, fig. 6 p. 81). Une tendance à l'aplatissement des fonds se manifeste dans ce groupe, et plus généralement à la fin du Néolithique moyen.

Enfin, une ressemblance du vase de Changis avec certains vases de la phase 3 du groupe de Roquefort (Roussot-Laroque, 1991, fig. $5 \mathrm{n}^{\circ}$ 6) pourrait sembler aberrante, si ce n'est qu'on
Fig. 13 - Changis-sur-Marne Les Pétreaux, Le Dessus de la Chaussée, profil du vase issu de la sépulture 20 (dessin : Y. Lanchon, INRAP).

Changis-sur-Marne Les Pétreaux, Le Dessus de la Chaussée, profile of the vessel from Burial 20 (drawing: Y. Lanchon, INRAP).

se situe chronologiquement, comme pour les autres rares comparaisons, à la fin du Néolithique moyen (deuxième tiers du $\mathrm{IV}^{\mathrm{e}}$ millénaire av. J.-C.).

\section{SÉPULTURE 21 (STRUCTURE 5433)}

\section{LA FOSSE ET SON COMBLEMENT}

La sépulture 21 se trouvait vers le sud-ouest, en bas de pente. La fosse d'implantation de cette tombe présentait un contour subcirculaire et un profil à parois obliques avec fond irrégulier. Profonde de $0,10 \mathrm{~m}$, elle mesurait $1,40 \mathrm{~m}$ de large par 1,60 m de long. Deux fosses distantes de $15 \mathrm{~cm}$ étaient recreusées dans la fosse principale. Un squelette se trouvait dans chacune de ces fosses. La fosse principale était ménagée dans un substrat sableux jaune. Son comblement se caractérisait par un limon sableux brun hétérogène assez foncé, perturbé par des terriers ; chacune des deux fosses recreusées présentant un comblement limoneux légèrement moins sableux, brun foncé à rouge, organique.

La fosse la plus au nord ayant accueilli les restes du sujet A, ovale, mesurait $1,05 \mathrm{~m}$ par $0,45 \mathrm{~m}$ et celle au sud qui abritait les restes du sujet $\mathrm{B}$, également ovale, mesurait $1,15 \mathrm{~m}$ pour $0,55 \mathrm{~m}$. Ces deux sujets n'apparaissaient pas à la même profondeur, le sujet A étant plus profondément enfoui que le B.

Trois éclats en silex blanc tertiaire furent retrouvés, dispersés sur le sujet A.

\section{LES INHUMÉS}

Le sujet A était orienté nord-ouest / sud-est, la tête au nord-ouest. Il reposait dans une position hypercontractée, très à l'étroit dans la fosse (fig. 14). La moitié supérieure de l'individu A était en procubitus, l'avant-bras droit replié sur le bras le long de la cage thoracique et le membre supérieur gauche fléchi à $100^{\circ}$. Les membres inférieurs étaient sur le côté gauche en hyperflexion et recouvraient le haut du corps. Ainsi les genoux étaient sur une même ligne que la ceinture du membre supérieur droit et les pieds à la hauteur du bassin.

Le sujet B était orienté nord-ouest / sud-est, la tête au sud-est. Le sujet B était replié sur le côté droit. Malgré des déplacements, les membres supérieurs étaient fléchis en avant de la cage thoracique. Les membres inférieurs étaient fléchis à environ $45^{\circ}$, le genou droit se retrouvant à hauteur de l'abdomen.

Les os coxaux de l'individu A étaient trop mal conservés pour permettre une détermination du sexe et de l'âge. Le sexe du sujet B était indéterminé, et il s'agissait d'un adulte de plus de 40 ans.

D'une manière générale, les épiphyses des os longs étaient moins bien conservées que les diaphyses. Le tissu spongieux 


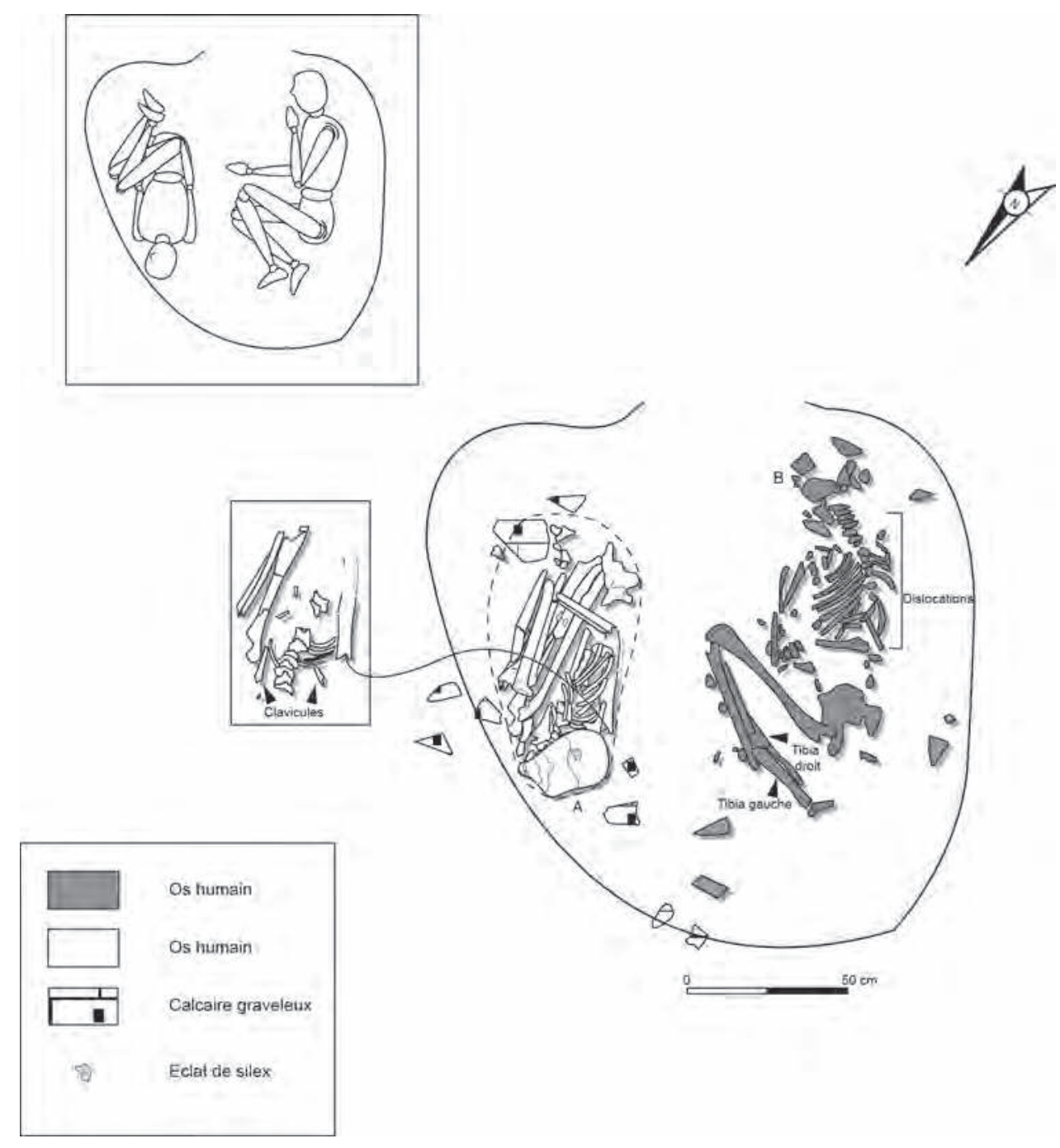

Fig. 14 - Changis-sur-Marne Les Pétreaux, Le Dessus de la Chaussée, plan de la sépulture 21 (DAO : J.-G. Pariat, SDAVO).

Changis-sur-Marne Les Pétreaux, Le Dessus de la Chaussée, plan of Burial 21 (graphics: J.-G. Pariat, SDAVO).

était préservé dans la plupart des cas. Les restes du sujet A, peu fragmentés, étaient inégalement représentés. La moitié supérieure du crâne n'était pas conservée, l'étage lombaire était absent, il n'y avait aucun fragment de sternum et la ceinture pelvienne était incomplète. Enfin, les petits os des extrémités étaient sous-représentés.

Les restes crâniens appartenant au sujet B étaient peu nombreux, certains os longs étaient totalement absents à gauche (humérus, os coxal, fémur) et les petits os des extrémités étaient à nouveau rares.

Plusieurs terriers ont été repérés dans le comblement de cette seconde fosse. D'ailleurs certains os longs plongeaient à la verticale dans le sol. Une grande partie des déficits observés s'explique en conséquence sans doute par l'action d'animaux fouisseurs. L'absence de certains os longs du type fémur, intransportables s'ils sont entiers par un animal fouisseur, doit être expliquée d'une autre manière. Dans ce cas précis, les labours répétés ont pu conduire à la destruction de pièces osseuses, tant la profondeur d'enfouissement est faible.

\section{ConNexions et disLocations}

Le sujet A était en connexion partielle. Le crâne a subi des déplacements. Il apparaissait en face supérieure. La mandibule était restée en connexion avec le crâne ainsi que les deux premières vertèbres cervicales.

Vertèbres cervicales et thoraciques étaient en connexion. Elles apparaissaient en face postérieure ou postérieure légèrement latérale. Il y avait un pendage dans le sens nord-sud, les vertèbres thoraciques situées au sud étant plus profondes. Les côtes gauches et droites étaient plus hautes que les vertèbres et apparaissaient en face postérieure à inférieure légèrement postérieure. Elles étaient pour la plupart en connexion lâche avec les vertèbres.

Les clavicules étaient verticalisées et les scapulas mises à plat. Les os de l'avant-bras droit étaient ramenés vers le bras droit, le long du corps. Tous les os du membre supérieur droit apparaissaient en face postérieure. La position du membre supérieur gauche était plus complexe. L'humérus gauche apparaissait en face postérieure le long du corps et avait subi 
un effet de contrainte, sans doute lié à la présence de la paroi la fosse au sud-ouest. Les os de l'avant-bras gauche étaient dans la continuité de celui du bras et apparaissaient en face antérieure dans le dos du sujet. Le degré de flexion entre le bras et l'avantbras avoisinait $100^{\circ}$.

Les restes de la ceinture pelvienne étaient fragmentés mais dans une position anatomique logique. Les os des membres inférieurs étaient en connexion lâche. Le fémur droit apparaissait en face latérale. L'articulation du genou droit était partiellement préservée. La patella avait chuté au fond de la fosse. Le tibia apparaissait en face latérale légèrement antérieure et la fibula n'était plus en équilibre sur le tibia. Le fémur gauche apparaissait en face postérieure et se trouvait déconnecté du tibia et de la fibula dont la position était comparable à celle des os de la jambe droite. Le tibia gauche était bloqué par la paroi de la fosse à l'est.

L'articulation des chevilles était disloquée. En revanche, les os du tarse, en connexion, apparaissaient en face supérieure. Un bloc de pierre de $10 \mathrm{~cm}$ sur $12 \mathrm{~cm}$ se trouvait à leur contact à l'est. D'une manière générale, aucun os n'outrepassait les limites de la fosse.

Le sujet B était en connexion. Malgré une forte fragmentation du bloc crânio-facial, la tête osseuse était sans doute proche de sa position d'origine. La cage thoracique était mise à plat. La première vertèbre cervicale était en connexion avec le bloc crânio-facial. Toutes les vertèbres apparaissaient en face antérieure parfois légèrement latérale. Les côtes gauches apparaissaient en face supérieure.

Les os de la ceinture du membre supérieur étaient déconnectés et fragmentés mais leur position, anatomiquement logique. Les membres supérieurs avaient subi de nombreux remaniements. L'humérus droit était fragmenté et remanié, un fragment de diaphyse apparaissant fiché à la verticale dans le sol. Il en allait de même des restes de l'avant-bras droit. La position de l'épiphyse proximale de l'ulna n'était pas compatible avec celle des petits os du carpe droit. L'humérus gauche était absent et les os de l'avant-bras déconnectés à mi-hauteur de la cage thoracique. Ces deux os apparaissaient en équilibre instable sur les vertèbres thoraciques. Les os des mains, peu nombreux et mélangés, laissaient apparaître quelques phalanges proximales proches de leur position d'origine.

Le bassin avait perdu son volume. Le sacrum apparaissait en face antérieure et l'os coxal droit en face médiale. La tête du fémur droit, qui se trouvait en face postérieure légèrement médiale, était en place dans l'acétabulum. L'articulation du genou droit était distendue mais les os en place. La position relative des os de la jambe droite était logique. À gauche, seuls les os de la jambe se trouvaient en déséquilibre sur les deuxtiers distaux de la jambe droite.

Les articulations des chevilles étaient préservées. L'ensemble du tarse droit, ainsi que le tarse gauche, étaient retournés si bien que le talus n'était plus en connexion, et la partie postérieure du calcanéus se retrouvait contre le tibia.

\section{Milieu de DÉCOMPOSITION ET TYPE DE STRUCTURE}

Chaque dépôt est primaire comme le prouvent la bonne représentation squelettique, la préservation des connexions ainsi que la présence de petits os. Il est plus difficile de se prononcer sur la contemporanéité des deux dépôts. La profondeur des fosses n'est pas la même. Le remplissage des fosses de chaque individu est comparable ce qui militerait plutôt en faveur d'une contemporanéité des dépôts. Cette impression est confortée par les deux datations radiocarbones sur os obtenues à partir d'échantillons prélevés sur chaque squelette ( $c f$. infra). Il s'agit donc très vraisemblablement d'une sépulture double.

Du point de vue du mode de décomposition des corps, la situation ne peut pas être tranchée en ce qui concerne l'individu A. La verticalisation des clavicules et la chute des patellas sont survenues à l'intérieur du volume du corps. Paradoxalement, l'articulation entre l'os occipital et la première vertèbre cervicale est rompue. L'espace très réduit de la fosse dans laquelle se trouve le sujet a de toute façon considérablement limité les déplacements éventuels. Pour le sujet B, des ossements sont en équilibre instable à l'image du tibia gauche. Mais globalement, le corps s'est décomposé dans un espace où la place était nettement plus importante que dans le cas du sujet A. Le rachis et les côtes sont d'ailleurs disloqués, le gril costal droit s'est ouvert. Toute une série de petits os ou de fragments se retrouve par ailleurs autour du corps. Il semble donc que le cadavre se soit décomposé en espace vide.

En somme les deux sujets ont été placés dans une fosse de grande taille et ont subi un traitement assez différent. Cette fosse a-t-elle pu accueillir un dispositif sépulcral ? Aucun indice ne permet de discuter cette hypothèse, si ce n'est peut-être son surdimensionnement. Dans ce cas, la place ménagée pourrait avoir permis l'insertion d'un coffrage notamment.

\section{SÉPULTURE 22 (STRUCTURE 5543)}

\section{LA FOSSE ET SON COMBLEMENT}

Située en bas de pente, au sud-ouest, la sépulture 22 se trouvait dans un chablis. Il fut donc particulièrement complexe d'identifier les contours de fosse avec certitude. Les restes humains apparaissaient essentiellement dans une poche de sédiment limoneux brun foncé sableux caillouteux légèrement cendreux de 1,10 m de long par 0,90 m de large. Par endroit, le sédiment pouvait être plus mélangé. Quant au substrat environnant, il correspondait vers l'est à une poche de sable jaune. Un limon brun clair sableux caillouteux formait une couronne tout autour de la poche. En coupe le profil était régulier, à fond arrondi et la profondeur avoisinait $0,10 \mathrm{~m}$.

\section{LES INHUMÉS}

La fosse recelait les restes de deux sujets apparus à une même profondeur et distants de $3 \mathrm{~cm}$, le sujet $\mathrm{B}$ se trouvant à proximité du bassin du sujet A (fig. 15).

Le sujet A était orienté nord-est / sud-ouest, la tête au nord-est. Il reposait en position fléchie sur le côté droit. Les membres supérieur et inférieur droit étaient fléchis à $45^{\circ}$. La position des membres gauche n'était pas observable, car les ossements étaient remaniés. 


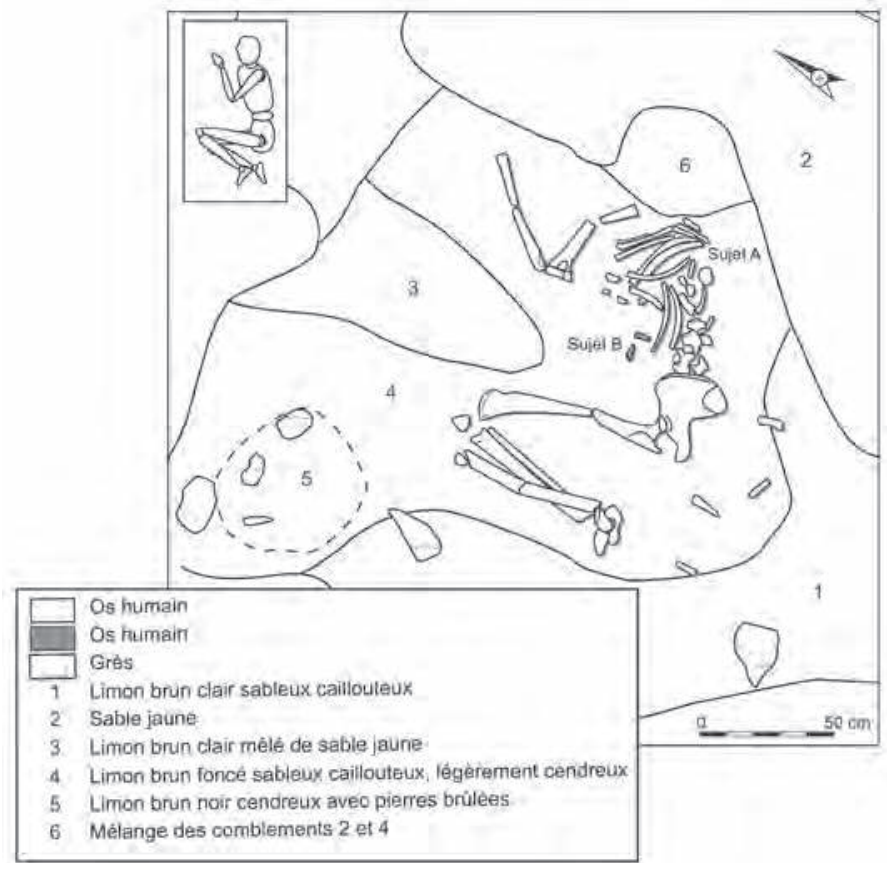

Fig. 15 - Changis-sur-Marne Les Pétreaux, Le Dessus de la Chaussée, plan de la sépulture 22 (DAO : J.-G. Pariat, SDAVO).

Changis-sur-Marne Les Pétreaux, Le Dessus de la Chaussée, plan of Burial 22 (graphics: J.-G. Pariat, SDAVO).

L'orientation et la position du sujet B n'étaient pas clair. Seuls deux os du membre supérieur gauche, en place (humérus, ulna), étaient fléchis à $90^{\circ}$.

Le sexe du sujet A était individu adulte de sexe féminin, son âge couvrant l'intervalle 30-59 ans.

L'individu B était un fœtus. Son âge fut être estimé à partir de trois restes osseux : les trois-quarts distaux de l'humérus gauche, la clavicule gauche et les trois-quarts proximaux du fémur droit. L'âge obtenu s'échelonnait entre 6 et 7 mois gestationnels.

La sépulture 22 renfermait donc un sujet adulte féminin et un fœtus de quelques mois. Les rares restes en place de ce dernier se trouvaient à $3 \mathrm{~cm}$ du bassin de l'adulte. Il est donc très probable que ce foetus ait été en place dans l'abdomen du sujet lors de l'inhumation.

Le tissu spongieux était conservé. Dans l'ensemble les diaphyses étaient plus nombreuses que les épiphyses des os longs.

La représentation squelettique du sujet A était moyenne. La tête osseuse était très incomplète, tout comme l'étage cervical. Il subsistait six vertèbres thoraciques et cinq vertèbres lombaires au niveau du tronc. Les grils costaux droit et gauche étaient presque complets. Par contre, il manquait le sternum.

Les ceintures des membres supérieurs étaient présentes à l'état de fragment, exception faite de la scapula gauche absente. Les membres étaient inégalement représentés. À droite, on recensait un fragment d'humérus, les deux os de l'avant-bras, deux métacarpiens et seulement deux phalanges proximales de main. À gauche, il restait deux os de l'avant-bras, un méta- carpien, une phalange proximale de main et deux phalanges moyennes.

L'os coxal droit était le seul os du bassin préservé. Les membres inférieurs étaient représentés à droite par le fémur, un fragment de patella, les os de la jambe et neuf ossements du pied, tandis qu'à gauche on recensait les os de la jambe et onze os pour le pied.

La tête osseuse du sujet B était absente. Au niveau de la cage thoracique, il subsistait deux arcs gauches de vertèbre cervicale et deux fragments droit ou gauche de côte. La ceinture des membres supérieurs était représentée par un fragment de clavicule gauche et les membres par deux fragments d'humérus droit et gauche, deux fragments d'ulna droit et gauche ainsi que par un métacarpien et deux phalanges proximales. Enfin, il ne subsistait des membres inférieurs qu'un fragment de fémur droit, deux fragments de tibia droit et gauche, et deux fragments de fibula droite et gauche.

Ces déficits relativement conséquents peuvent être expliqués d'une part par la faible profondeur d'enfouissement, d'autre part par les perturbations occasionnées par les animaux fouisseurs. En effet, les squelettes étaient peu profondément enfouis sous la surface actuelle du sol et, dans le cas du sujet A la moitié gauche était surélevée par rapport à la moitié droite puisque le corps reposait sur le côté droit. Les perturbations occasionnées par les labours furent donc sans doute largement responsable des manques observés.

Par ailleurs des terriers ont été repérés au moment de la fouille impliquant le passage d'animaux fouisseurs, qui ont de fait pu engendrer des remaniements.

\section{Connexions et dislocations}

Le sujet A était en place. L'étage thoracique était disloqué dans sa partie supérieure puis en connexion à partir de la quatrième vertèbre. Enfin l'étage lombaire était en connexion laissant apparaître les vertèbres par leur face latérale gauche. Côtes droites et gauches étaient perturbées.

L'articulation de l'épaule droite était rompue mais la position du membre était anatomiquement logique. Le coude était en connexion lâche. Les os des extrémités étaient absents.

L'articulation de la hanche droite était maintenue. Au lieu d'apparaitre en face latérale, la patella droite apparaissait par sa face antérieure trahissant une dislocation du genou. Tibia et fibula étaient dans une position proche de celle d'origine. À gauche, le tibia était sans doute proche de la position qu'il avait à l'origine, la partie distale de la diaphyse reposant sur celle du tibia droit.

Les talus droit et gauche étaient en connexion avec chaque tibia. Par ailleurs les os du tarse antérieur gauche reposaient sur ceux du tarse droit. Métatarsiens et phalanges étaient déconnectés. Quelques petits os, exclusivement des métatarsiens situés au sud de l'individu au niveau du membre inférieur, sortaient du volume initial de décomposition du cadavre.

Les os de l'individu B avaient subi des remaniements et seuls deux d'entre eux restaient en place. Il s'agissait d'os du membre supérieur gauche. Leur agencement était logique, bien qu'ils fussent déconnectés. La partie proximale de l'ulna située à $1 \mathrm{~cm}$ de la partie distale de l'humérus se trouvait dans son prolongement. 


\section{Milieu DE DÉCOMPOSITION ET TYPE DE STRUCTURE}

Fortement perturbée, la sépulture 22 présente néanmoins les caractéristiques d'un dépôt primaire. Les connexions abondent et la logique anatomique est respectée. Il reste impossible de se prononcer sur l'aspect individuel ou pluriel de ce dépôt, car la tombe est très érodée et implantée sur un chablis.

L'absence de la plupart des restes crâniens du sujet A est frappante. On remarque que la première vertèbre cervicale (atlas) est manquante. Cela est sans doute à mettre en relation avec une perturbation exogène, comme semble le montrer la différence de nature du comblement au niveau de la tête.

Le milieu de décomposition pose problème compte tenu de l'intensité des remaniements. Cependant le maintien de certaines connexions anatomiques (os coxal droit / fémur droit, genou droit, tarses droit et gauche) ainsi que la station en équilibre instable des côtes gauches, du tibia gauche et du pied gauche suggèrent une décomposition en espace colmaté. Concernant le sujet B, il y a trop peu de restes en place pour discuter du milieu de décomposition.

\section{SÉPULTURE 23 (STRUCTURE 5805)}

\section{LA FOSSE ET SON COMBLEMENT}

La sépulture 23, en bas de pente, était la plus au nord de toutes les tombes, dans une zone régulièrement inondée du fait de la proximité d'un ancien chenal de la Marne. Cette structure était donc en partie dégradée lors de sa découverte. Seule la moitié sud-ouest était conservée. À cet endroit, la fosse était sub-circulaire mesurant $90 \mathrm{~cm}$ d'ouest en est par $50 \mathrm{~cm}$ du nord au sud, et le profil du creusement était en cuvette.

Le remplissage était caractérisé par un limon brun se démarquant nettement de la grave (fig. 16). Il comblait la fosse sépulcrale sur une dizaine de centimètres d'épaisseur. Un vase, quelques restes humains et des blocs de grès apparaissaient dès la surface du décapage.

\section{L'INHUMÉ}

Les ossements appartenaient en fait à un sujet orienté ouest / est, avec la tête à l'ouest, la face tournée vers le sud-est. L'individu, qui occupait toute la surface conservée de la fosse, reposait vraisemblablement en position fléchie sur le côté droit mais sa position exacte n'était pas observable a priori.

Ce squelette appartenait à un enfant âgé de 3 ans 8 mois à 6 ans 9 mois.

Leétat général de l'os était médiocre. Le tissu spongieux n'était pas conservé dans la plupart des os longs. Les restes étaient dans l'ensemble très fragmentés, et les épiphyses faisaient cruellement défaut.

La tête osseuse était incomplète, contrairement à la mandibule. Très endommagée, la cage thoracique était représentée par les deux premières vertèbres cervicales, quatre fragments de vertèbres cervicales, et deux fragments de vertèbre thoracique. Seules six fragments de côte étaient conservés. La ceinture des membres supérieurs était seulement représentée par deux fragments de clavicule droit et gauche, et un fragment de scapula droit. Il subsistait au niveau des membres supérieurs deux fragments d'humérus, un fragment d'ulna et trois phalanges de main. La ceinture des membres inférieurs était représentée
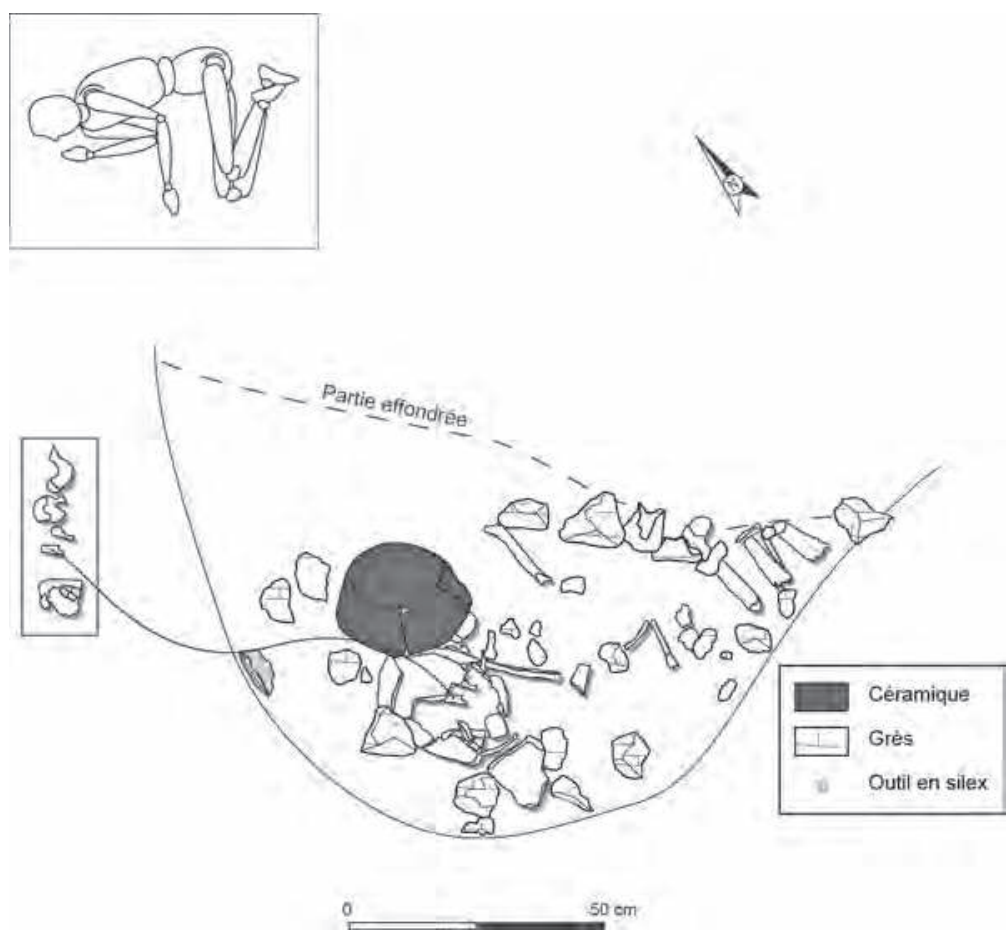

Fig. 16 - Changis-sur-Marne Les Pétreaux, Le Dessus de la Chaussée, plan de la sépulture 23 (DAO : J.-G. Pariat, SDAVO).

Changis-sur-Marne Les Pétreaux, Le Dessus de la Chaussée, plan of Burial 23 (graphics: J.-G. Pariat, SDAVO). 
par un fragment de première vertèbre sacrée. Enfin il restait seulement deux fragments de diaphyse de tibia droit et gauche, et deux fragments de diaphyse de fibula droite et gauche.

Ces déficits conséquents sont imputables à la forte érosion qui a affecté cette tombe (labours, inondation etc.).

\section{Connexions et Dislocations}

Le crâne, en face latérale gauche légèrement inférieure, n'était plus en connexion avec la mandibule. Au niveau de la cage thoracique les deux premières vertèbres cervicales étaient en connexion mais l'articulation du cou était disloquée. Les autres vertèbres cervicales et thoraciques étaient déconnectées, ainsi que les fragments de côte.

Au niveau de l'épaule droite, la clavicule et la scapula en face supérieure étaient déconnectées, sous le crâne. L'humérus droit situé au-dessous du gauche à quelques centimètres au sud-ouest de ce dernier apparaissait en face antérieure. De rares phalanges de main se trouvaient sous le crâne.

À gauche la clavicule était sans doute proche de sa position originelle. L'humérus gauche apparaissait en face latérale et avait subi un déplacement du sud-ouest vers le nord-est. Ainsi l'articulation du coude était, elle aussi, rompue. L'ulna gauche apparaissait en face médiale à quelques centimètres au sud-est de l'humérus.

L'unique fragment de vertèbre sacrée était remanié dans la terre d'effondrement. Du côté droit comme du côté gauche, chaque fragment de diaphyse fémorale apparaissait en face postérieure et le premier quart de la diaphyse du tibia gauche était en face médiale. Ces restes étaient en déséquilibre en bordure de la zone effondrée.

\section{Milieu de décomposition et TYPE DE StRUCtURE}

Les perturbations qui affectent cette tombe sont nombreuses et pour la plupart liées à des inondations répétées, ce qui complique fortement l'interprétation.

Malgré des déficits, le dépôt effectué pourrait bien être primaire comme l'atteste l'agencement cohérent des ossements les uns par rapport aux autres ainsi qu'une représentation squelettique au final assez équilibrée. Hélas l'effondrement d'une partie de la fosse empêche de savoir si un autre sujet se trouvait dans la même fosse. On ne peut donc conclure sur la nature individuelle ou multiple de ce dépôt.

Les observations taphonomiques ne permettent guère de préciser la position d'inhumation originelle de ce cadavre. Le bloc crânio-facial, qui apparaît par sa face latérale gauche et le membre supérieur gauche dont la profondeur est plus faible que celle du membre supérieur droit semble confirmer une inhumation d'un sujet fléchi sur le côté droit.

\section{Le MOBILIER}

Un vase, retourné à l'envers de telle sorte que le fond apparaisse dès la surface, était au contact du crâne. L'ouverture du récipient était orientée vers l'os occipital du sujet. Outre cet objet, un micro-denticulé en silex fut retrouvé en bordure ouest de la fosse, dans la partie supérieure du remplissage (détermination : V. Brunet, INRAP).
Le vase complet découvert dans la tombe 23 présentait un bord évasé et un fond plat (fig. 17). La pâte, bien cuite est de couleur brun-cuir à noir à l'extérieur, brun à l'intérieur. La cassure est noire. Le lissage externe a été effectué à la technique de la "main mouillée ». La pâte a été dégraissée à l'aide de silex concassé, dont d'assez nombreux grains, millimétriques, sont visibles en surface du vase. Deux mamelons imperforés ont été rapportés à $1,5 \mathrm{~cm}$ sous le rebord ; ils sont assez éloignés l'un de l'autre $(4,5 \mathrm{~cm})$, mais ce couple est unique (le vase est complet) ; il est difficile de parler de moyens de préhension, compte tenu de leur faible proéminence et de cette unicité. On doit plutôt les assimiler à un décor. Ce vase renvoie

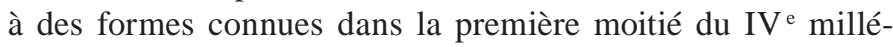
naire av. J.-C. en secteur Seine-Yonne (Henocq-Pochinot et Mordant, 1991, p. 202).

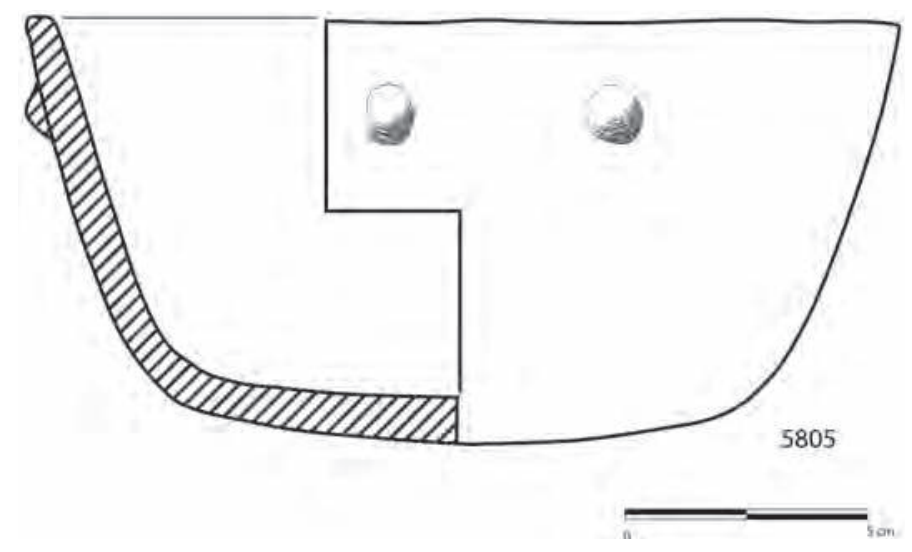

Fig. 17 - Changis-sur-Marne Les Pétreaux, Le Dessus de la Chaussée, profil du vase issu de la sépulture 23 (dessin : Y. Lanchon, INRAP).

Changis-sur-Marne Les Pétreaux, Le Dessus de la Chaussée, profile of the vessel from Burial 23 (drawing: Y. Lanchon, INRAP).

\section{SÉPULTURE 31 (STRUCTURE 8081)}

\section{LA FOSSE ET SON COMBLEMENT}

La sépulture 31 fut découverte dans la partie sud de l'emprise, en bas de pente. Un squelette reposait dans une fosse ovale d'environ $1,30 \mathrm{~m}$ de large pour $2,10 \mathrm{~m}$ de long, creusée dans la grave jusqu'à $0,30 \mathrm{~m}$ sous la surface du décapage (fig. 18). Les dimensions du creusement outrepassaient largement l'espace occupé par le corps du défunt. En coupe le profil de la fosse était à fond plat et les parois, subverticales. Le comblement se caractérisait par un limon brun sableux recelant de nombreux cailloux. Aucun mobilier ne fut découvert, en dehors d'un tesson peu caractéristique, à $8 \mathrm{~cm}$ sous la surface du décapage.

\section{L'INHUMÉ}

Le squelette se trouvait à une vingtaine de centimètres sous la surface du décapage. Il était orienté nord-nord-est / sud-sudouest, la tête au nord-est, et reposait en position fléchie sur le 


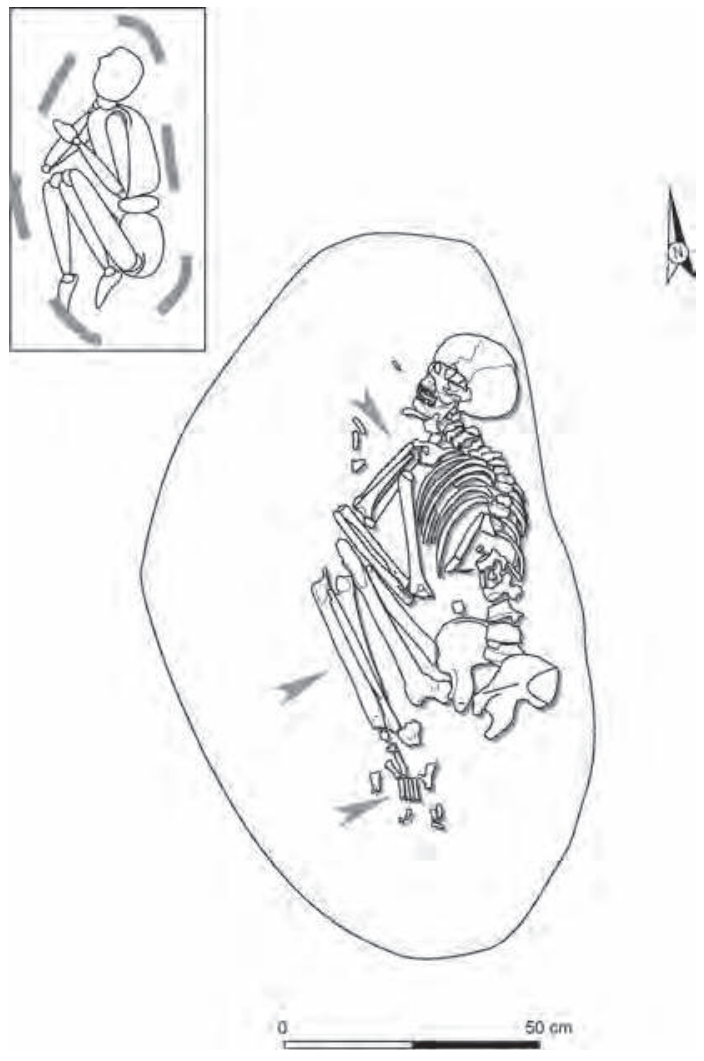

Fig. 18 - Changis-sur-Marne Les Pétreaux, Le Dessus de la Chaussée, plan de la sépulture 31 (DAO : J.-G. Pariat, SDAVO).

Changis-sur-Marne Les Pétreaux, Le Dessus de la Chaussée, plan of Burial 31 (graphics: J.-G. Pariat, SDAVO).

côté droit. Le degré de flexion de l'avant-bras sur le bras droit était maximal. La main devait initialement se trouver sous le menton du défunt. À gauche l'avant-bras était ramené vers le bras, formant un angle d'environ $45^{\circ}$. La main se trouvait vraisemblablement dans le prolongement de l'avant-bras, au nord-est des genoux. Les membres inférieurs étaient hyperfléchis, la jambe formant avec la cuisse droite un angle de $25^{\circ}$ environ. La flexion était plus forte encore à gauche $\left(15^{\circ}\right)$. Les pieds étaient en extension dans le prolongement des jambes.

L'individu inhumé était un adolescent d'âge compris entre 9 ans 11 mois et 17 ans 3 mois.

Les surfaces osseuses étaient fortement érodées : les os longs comportaient de nombreuses traces vermiculées caractéristiques de radicelle. Malgré cette mauvaise conservation des surfaces, le tissu spongieux était présent dans les diaphyses des os longs.

Le squelette était globalement bien représenté. La tête osseuse était complète. Il ne manquait pas d'os au niveau du squelette axial, en dehors d'un fragment de sacrum et du coccyx. Le sternum était représenté par un fragment de manubrium et par deux fragments de corps.

Concernant le squelette appendiculaire, tous les os de la ceinture des membres supérieurs étaient présents. Les os des bras et des avant-bras étaient bien représentés contrairement à ceux des mains. Le carpe était absent à droite comme à gauche.
Les métacarpiens étaient présents en dépit d'une importante fragmentation. Les phalanges étaient inégalement représentées et leur fragmentation était variable.

Les os coxaux étaient complets aux trois-quarts. Les os des cuisses et des jambes étaient présents, à l'exception de la patella gauche. Il manquait néanmoins plusieurs épiphyses, en particulier au niveau du membre gauche. Le pied droit était représenté par douze ossements soit quatre os du tarse, cinq métatarsiens, deux phalanges proximales et une phalange distale. À gauche, le profil était équivalent avec trois os du tarse, cinq métatarsiens et deux phalanges proximales.

\section{Connexions et dislocations}

Le bloc crânio-facial apparaissait en face latérale gauche, la face regardant vers le nord-ouest. La mandibule, elle aussi en face latérale gauche, était en connexion avec le crâne. La première vertèbre cervicale était en connexion avec la partie basilaire de l'os occipital. La seconde était en place. L'articulation du cou était ensuite rompue au niveau de la troisième vertèbre cervicale. Le reste de l'étage cervical ainsi que les neuf vertèbres thoraciques suivantes étaient en connexion. Leur face d'apparition variait de postérieure latérale gauche à postérieure du nord-est vers le sud-ouest. Les vertèbres 9 à 12 étaient disloquées sans être dispersées toutefois. Enfin, les cinq vertèbres lombaires étaient légèrement déconnectées et apparaissaient en face postérieure. Les côtes droites étaient en connexion avec les vertèbres. Elles apparaissaient en face postérieure ou postéro-inférieure. Les côtes gauches, en connexion lâche avec les vertèbres, apparaissaient également en face postérieure ou postéro-inférieure. Le sternum se trouvait sous les côtes gauches, en face postérieure.

La ceinture des membres supérieurs était remaniée. La clavicule droite, «verticalisée », se trouvait en face postérieure, déconnectée de la scapula, elle aussi en face antérieure. À gauche, la scapula avait légèrement glissé d'est en ouest, en étant toutefois restée en équilibre instable sur les premières côtes gauches. Elle apparaissait en face postéro-inférieure. La clavicule, tombée sur l'humérus droit, en face postérieure, était déconnectée de la scapula. Le membre supérieur droit était hyperfléchi, peut-être consécutivement à une contrainte exercée au nord. L'articulation de l'épaule était disloquée, celle du coude légèrement déconnectée. L'humérus droit, en face médiale, était peu remanié. L'ulna croisait le radius. La main était disloquée en avant de la face. Le membre supérieur gauche était fléchi à $45^{\circ}$, la main se retrouvant à mi-hauteur du thorax. L'articulation de l'épaule était distendue. L'humérus apparaissait en face postérieure légèrement latérale. L'articulation du coude était maintenue. L'ulna était en face médiale et le radius, en face postérieure, avait basculé d'ouest en est.

Le bassin avait subi de forts remaniements aboutissant à la disparition de son volume. L'os coxal droit était déconnecté du sacrum. Il était en face médiale avec la crête à l'est. Le fémur était déconnecté de ce dernier et apparaissait en face postéromédiale. L'articulation du genou droit était rompue. La patella avait migré en amont de l'os coxal gauche. Le tibia droit, proche de sa position d'origine, apparaissait en face médiale. La cheville était en connexion, talus et calcanéus en face médiale, entre le tibia et le naviculaire. Un bloc de quatre métatarsiens 
s'était effondré de face médiale en face postérieure. Les phalanges étaient déconnectées mais faiblement dispersées. Elles se trouvaient dans le prolongement des métatarsiens. L'os coxal gauche déconnecté du sacrum était en face postérieure, la partie supérieure orientée vers le nord-est. Le fémur, en face antérieure, avait légèrement basculé sans que son épiphyse proximale ne sorte pour autant de la cavité acétabulaire. L'articulation du genou était distendue. Le tibia apparaissait en face latérale légèrement antérieure, sous la fibula globalement restée en déséquilibre en face latérale à antérieure. Cette jambe avait semble-t-il subi une contrainte à l'ouest. L'articulation de la cheville n'était pas aussi bien préservée qu'à droite. Le talus était en place en face latérale, mais les autres os du pied étaient disloqués et faiblement dispersés. Le premier métatarsien était en face latérale. Deux autres métatarsiens, non déterminés, avaient une position anatomiquement logique. Leur partie distale était orientée vers le sud. Le cinquième métatarsien gauche était en face dorsale, au-dessus de la seconde rangée du tarse droit. Par ailleurs, à droite comme à gauche, les os des pieds avaient semble-t-il subi la même contrainte que la jambe gauche, à l'ouest.

\section{MiLIEU de déCOMPOSITION et TYPE D'ARCHITECTURE}

La nature du dépôt ne pose pas de problème. Le sujet s'est décomposé sur place dans la fosse. En témoignent la logique anatomique qui se dégage de cet ensemble, l'abondance des connexions et la bonne représentativité du squelette.

Les dislocations sont multiples. L'étage cervical est partiellement déconnecté. L'étage lombaire est remanié. L'épaule droite est disloquée. On observe une «verticalisation » de la clavicule. Les mains sont déconnectées. L'articulation de la hanche droite est rompue. Le genou n'est pas en connexion. La patella se trouve en amont de l'os coxal gauche, loin de sa position d'origine. Les os des pieds ont subi des perturbations. On constate par exemple un basculement du bloc de métatarsiens droits. Ces nombreux indices traduisent l'évolution du corps au sein d'un espace vide.

Ce milieu de décomposition n'a pu exister à la seule condition qu'un dispositif ait ménagé les vides. Outre une fosse assez large par rapport à l'espace occupé par le corps, plusieurs indices suggèrent la présence d'un contenant de type enveloppe souple et rigide (natte, linceul, sac). L'épaule droite est verticalisée et projetée vers l'avant sans doute du fait de l'exiguïté du contenant. Par ailleurs, le bassin est disloqué sans mise à plat des os coxaux. Enfin des effets de contrainte ponctuels affectent les membres inférieurs.

La présence d'une enveloppe souple n'empêche pas l'existence d'autres dispositifs architecturaux. Tous les remaniements observés ne sont d'ailleurs pas forcément liés à la présence de cette enveloppe. La colonne vertébrale et le bassin ont ainsi subi des perturbations pour le moins surprenantes. L'étage thoracique est peu bouleversé par rapport aux vertèbres cervicales et lombaires. L'os coxal droit a subi une rotation et le sacrum est déconnecté de ce dernier. Trois hypothèses d'interprétation sont envisageables face à ce constat. La première met en avant le rôle d'animaux fouisseurs dont l'action aurait engendré des déplacements. Elle est difficile à imaginer car les déplacements observés portent sur de faibles distances et nous n'avons remarqué aucune trace de terrier. La seconde piste privilégie le scénario d'un unique dispositif de protection : une enveloppe souple, très contraignante, a pu lors de sa disparition engendrer des dislocations et des ruptures très nettes de la logique anatomique par « relâchement ». Toutes les parties du corps n'auraient pas subi des contraintes aussi fortes les unes par rapport aux autres, ce qui expliquerait que certaines parties du squelette soient restées en place. La troisième piste fait la part belle à la présence d'un fond rigide en matière périssable. La disparition de ce fond aurait engendré la chute de certaines portions de corps dans des espaces vides résiduels. Les dislocations partielles pourraient en être la conséquence.

En résumé, la fosse a accueilli un corps dont la décomposition s'est faite in situ. Le défunt était apparemment placé dans une enveloppe souple. Nous n'avons en revanche que peu d'indices en faveur de la présence d'un dispositif architectural «secondaire » (couverture, fond...).

\section{DES FAITS AUX GESTES}

\section{CHRONOLOGIE DE L'OCCUPATION}

Seuls deux vases issus des tombes 20 et 23 ont permis de proposer un rattachement chronologique à la première moitié du $\mathrm{IV}^{\mathrm{e}}$ millénaire av. J.-C. L'examen de ces deux récipients révèle des similitudes avec des formes attestées sur les sites de Noyen-sur-Seine Le Haut des Nachères (Mordant C. et D., 1972) et Balloy Gros Bois (Mordant, 1967).

Par ailleurs les deux pièces osseuses issues de la sépulture 5 viennent alimenter la discussion chronologique. L'outil appointé est d'un type fréquemment rencontré dans les contextes Cortaillod, Michelsberg et Néolithique Moyen Bourguignon. En revanche, la présence d'un pic en bois de cerf paraît plus originale dans un tel contexte.

Face à l'indigence de ce mobilier caractéristique (deux récipients pour dix tombes), il fut décidé de réaliser des datations absolues pour chaque tombe dont le rattachement au Néolithique moyen était supposé. Ainsi les dix tombes précédemment décrites ont été datées, l'une des sépultures plurielles (sépulture 21) faisant même l'objet de deux mesures. Au final onze datations ont été effectuées, ce qui constitue un corpus de référence conséquent pour cette période du Néolithique dans le Bassin parisien.

Les résultats obtenus couvrent l'essentiel du $\mathrm{IV}^{\mathrm{e}}$ millénaire av. J.-C. (fig. 19). Les dates se répartissent entre 4200 et 3300 av. J.-C. Dans le détail les sépultures peuvent être scindées en trois grands blocs renvoyant à trois phases qui ne se chevauchent pas.

La première phase rassemble les tombes 23 et 31 qui

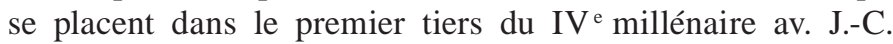
(4000-3750 av. J.-C.). Les données de Changis ne permettent pas de faire coïncider pratiques funéraires, culture matérielle et datations radiocarbones, notamment du fait de l'absence de mobilier dans la plupart des tombes. Cependant les sites connus pour la période correspondant à la phase 1 dans la zone géographique du sud Seine-et-Marne se rattachent tour à tour au Michelsberg, au groupe de Noyen ou bien encore 


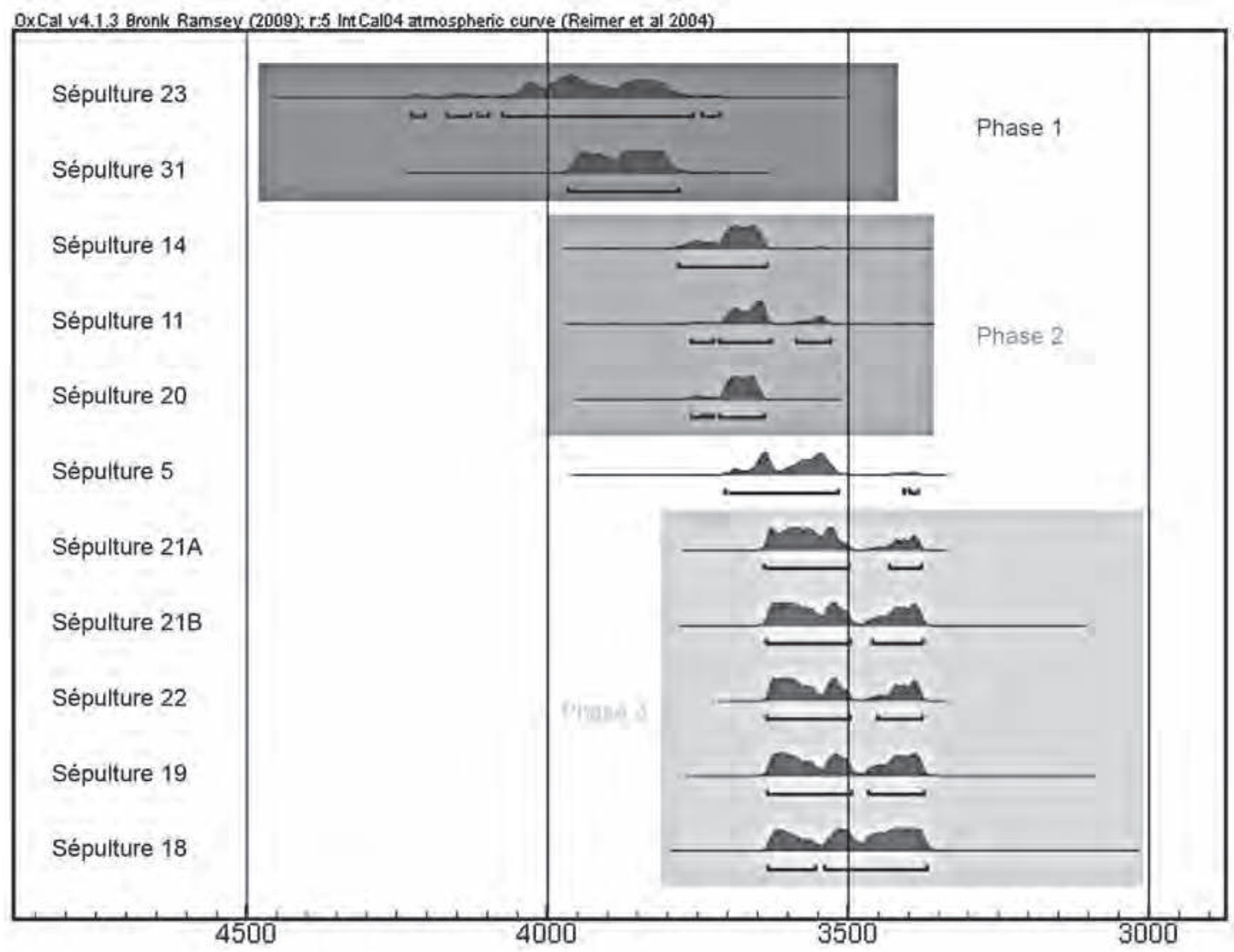

\begin{tabular}{|c|c|c|c|c|}
\hline $\mathrm{N}^{\circ}$ sépulture & $\mathrm{N}^{\circ}$ structure & Laboratoire & Date BP & Date BC \\
\hline 23 & 5805 & GrA-33997 & $5140 \pm 80$ & $\begin{array}{l}4227-3713(2 \sigma) \\
4076-3758(1 \sigma)\end{array}$ \\
\hline 31 & 8081 & GrA-29365 & $5075 \pm 40$ & $3965-3782(2 \sigma)$ \\
\hline 14 & 2711 & GrA-34608 & $4900 \pm 45$ & $3782-3635(2 \sigma)$ \\
\hline 11 & 2370 & Ly-11414 & $4865 \pm 45$ & $\begin{array}{l}3762-3530(2 \sigma) \\
3725-3628(1 \sigma)\end{array}$ \\
\hline 20 & 5695 & Ly-11543 & $4905 \pm 30$ & $\begin{array}{l}3761-3640(2 \sigma) \\
3715-3640(1 \sigma)\end{array}$ \\
\hline 5 & 1025 & Ly-7613 & $4820 \pm 50$ & $\begin{array}{l}3706-3384(2 \sigma) \\
3706-3516(1 \sigma)\end{array}$ \\
\hline $\begin{array}{c}21 \\
\text { Sujet A } \\
\text { Sujet B }\end{array}$ & 5433 & $\begin{array}{l}\text { Ly-11417 } \\
\text { Ly-11418 }\end{array}$ & $\begin{array}{l}4755 \pm 40 \\
4735 \pm 45\end{array}$ & $\begin{array}{l}3640-3379(2 \sigma) \\
3640-3499(1 \sigma) \\
3637-3376(2 \sigma) \\
3637-3496(1 \sigma)\end{array}$ \\
\hline 22 & 5523 & Ly-11419 & $4735 \pm 35$ & $\begin{array}{l}3636-3377(2 \sigma) \\
3636-3497(1 \sigma)\end{array}$ \\
\hline 19 & 5689 & Ly-11420 & $4725 \pm 45$ & $\begin{array}{l}3635-3375(2 \sigma) \\
3635-3494(1 \sigma)\end{array}$ \\
\hline 18 & 4141 & Ly-11416 & $4705 \pm 55$ & $\begin{array}{l}3634-3370(2 \sigma) \\
3530-3370(1 \sigma)\end{array}$ \\
\hline
\end{tabular}

Fig. 19 - Histogramme de calibration des datatations radiocarbones sur os (les courbes ont été réalisées à partir du logiciel Oxcal 4.1.3 (c) Bronk Ramsey 2009). 
au Néolithique Moyen Bourguignon de l'Yonne tel qu'il a été récemment redéfini (Moreau, 2010).

Une seconde phase peut être définie à partir des tombes 11, 14 et 20. Elle couvre une période comprise entre 3780 et 3630 av. J.-C. caractérisant, dans la région, des horizons récents du Michelsberg, du groupe de Balloy ou du Néolithique Moyen Bourguignon.

La datation obtenue pour la tombe 5 (3706-3384 av. J.-C.) assure une sorte de transition entre les phases 2 et 3 . La troisième et dernière phase réunit les sépultures 18, 19, 21 et 22. La fourchette chronologique couverte s'étend entre 3640 et 3370 av. J.-C. Par conséquent, ces tombes se placent soit à l'extrême fin du Néolithique moyen soit à l'aube du Néolithique récent, période qui débute vers 3400 av. J.-C. (Augerau et al., 2007).

Ces résultats confirment les datations proposées pour les tombes 20 et 23 à partir de la céramique. La sépulture 23 renvoie ainsi à une phase plus ancienne de l'occupation du site que la tombe 20.

L'examen de la distribution spatiale des tombes en fonction des phases d'occupation révèle une forte dispersion, en particulier durant la phase 1 où la tombe 23 se trouve au nord de l'emprise, à l'opposé de la sépulture 31 qui en est contemporaine. Les sépultures de la phase 2 , si elles sont plus proches les unes des autres, restent pourtant éloignées. La situation n'est guère différente concernant les tombes de la phase 3 : les sépultures 21 et 22 sont proches mais éloignées des tombes 18 et 19 .

\section{LES FOSSES SÉPULCRALES}

La morphologie des fosses sépulcrales est semble-t-il soumise à de fortes variations quelle que soit la phase concernée. Trois fosses sont de plan ovale, trois de plan subcirculaire, deux ont un contour irrégulier, une présente un plan carré à bords arrondis et la dernière est illisible.

L'examen des profils conduit au même constat. Dans quatre cas les fosses présentent des parois obliques et un fond irrégulier, dans deux cas leur profil est en cuvette, et dans deux autres cas les parois sont sub-verticales à fond plat ou irrégulier. Enfin dans un cas les parois sont obliques à fond arrondi, et dans le dernier cas le profil est illisible.

Ainsi la préparation des fosses sépulcrales ne paraît pas particulièrement standardisée et soignée. Cependant l'existence de parois obliques pourrait être la conséquence d'une forte érosion de parois à l'origine verticales. Les profondeurs des fosses semblent corroborer ce scénario. En effet, les fosses à parois su-verticales sont en général plus profondes (sépultures 14 et 31), donc moins érodées, que les fosses à parois obliques (sépultures 11, 21, 22).

Les différences de profondeur d'enfouissement depuis la surface du décapage soulèvent par ailleurs un problème de représentativité. Les tombes $11,21,22$ et 23 , très peu profondes, peuvent être considérées comme affleurantes. Par chance elles ont malgré tout résisté à l'épreuve du temps et à l'action de l'érosion. Mais l'on peut s'interroger sur la destruction complète de tombes plus superficielles, dont il ne subsisterait pas la moindre trace dans le paysage. Autrement dit, les tombes auraient été à l'origine plus nombreuses.
À Changis, une fosse mesure en moyenne 1,40 m de long pour $1 \mathrm{~m}$ de large. Ces dimensions abritent malgré tout de fortes disparités. Il paraît plus pertinent de considérer la taille des fosses sépulcrales par rapport à l'espace réellement occupé par les squelettes. Dans six cas la fosse est clairement surdimensionnée, tandis que dans deux cas la fosse est moins large (sépultures 14 et 31). Enfin dans deux tombes l'érosion est trop importante pour se prononcer (sépultures 22 et 23).

Quant au comblement des fosses lui-même, c'est peut-être l'aspect où l'on observe les variations les plus faibles, ce qui est normal. En effet le sédiment ayant été extrait des fosses a sans doute ensuite servi de remblai. Le sédiment correspond donc toujours à un limon brun foncé. Les différences portent en fait sur les composantes sableuses et les inclusions éventuelles de cailloutis liées à la nature du substrat.

\section{II.3- LES DISPOSITIFS SÉPULCRAUX}

\section{LES CONTENANTS}

Deux grandes familles de contenant se distinguent parmi les tombes de Changis : les enveloppes souples et rigides d'une part (sépultures 14, 31); les contenants rigides fixes ou mobiles d'autre part (sépultures $5,18,19,20)$. Ces derniers se scindent en deux catégories, les coffres ou les coffrages, que l'approche taphonomique ne permet pas toujours de distinguer à Changis. Certains de ces contenants rigides peuvent avoir fait l'objet d'un aménagement secondaire, à l'instar de la tombe 20 où enveloppe souple et coffre / coffrage ne s'excluent pas.

À Changis la présence d'un coffre ou d'un coffrage dans une fosse sépulcrale est attestée, d'après les ${ }^{14} \mathrm{C}$, à partir de $3700 \mathrm{av}$. J.-C. et jusqu'à 3300 av. J.-C. Cette période chronologique est encore méconnue du point de vue des pratiques funéraires dans le Bassin parisien. Toutefois l'existence de coffres ou de coffrages semble avoir été repérée sur d'autres sites. Ainsi à Dampmart Les Sables (Seine-et-Marne), un coffre pourrait avoir accueilli deux sujets dont une réduction (Bulard, 1989, fig. 20). On peut aussi faire le rapprochement avec la sépulture 4 de Grisy-sur-Seine Les Roqueux (Seine-et-Marne) pour laquelle l'hypothèse d'une sépulture en coffre a été proposée (Mordant, 1987).

En somme, les dispositifs de type coffre ou coffrage sont connus pour cette période mais leur recensement est à faire. Ce dernier, couplé à une approche chronologique fine des sites, pourrait alimenter les recherches sur les tombes en coffre et sur l'émergence du mégalithisme dans le Bassin parisien ; l'omniprésence des chambres funéraires en bois dans les allées sépulcrales pouvant puiser son origine dans des dispositifs sépulcraux comparables à ceux expérimentés par les hommes de Changis.

\section{UN SIGNALEMENT EN SURFACE DES TOMBES ?}

La forte dispersion des tombes amène à s'interroger sur leur éventuel signalement en surface. Trois sépultures offrent des pistes de réflexion à ce sujet.

La tombe 14 n'a pas pu être l'objet d'un signalement en surface, du moins de façon pérenne, puisqu'elle est recoupée par une structure plus récente datée des âges des Métaux. 


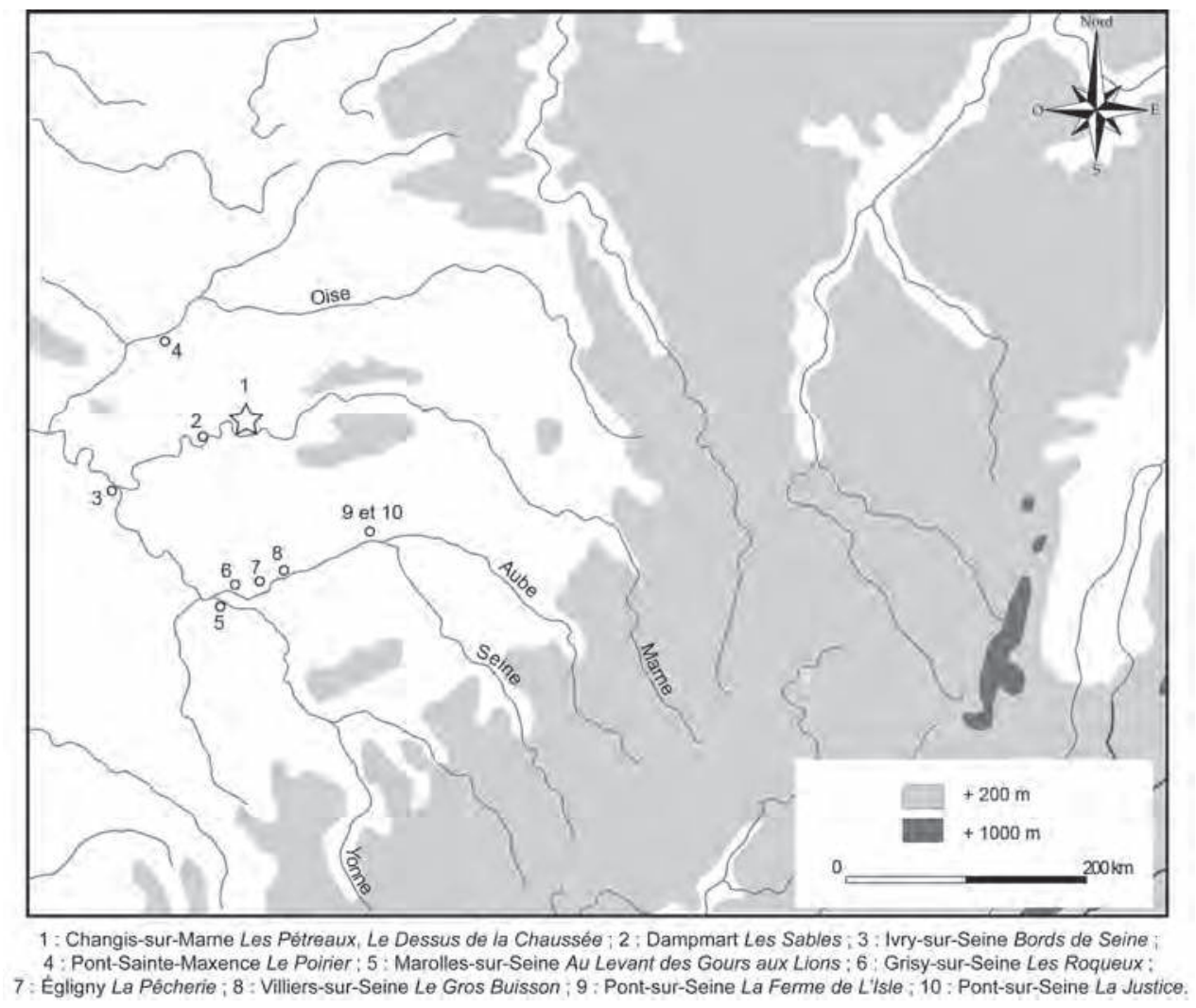

Fig. 20 - Sites funéraires du IVe millénaire av. J.-C. identifiés dans le sud-est du Bassin parisien (DAO : J.-G. Pariat, SDAVO). Funerary sites of the $4^{\text {th }}$ millennium BC identified in the south-east of the Paris Basin (graphics: J.-G. Pariat, SDAVO).

On peut par contre formuler l'hypothèse d'un marquage pour les sépultures 19 et 20 . Dans le cas de la sépulture 20, un bloc de grès assez conséquent se trouvait au-dessus de la fosse. Peut-être appartenait-il à un système de repérage de la tombe. Mais c'est sans commune comparaison avec l'imposante dalle de grès de trois tonnes qui recouvrait la sépulture 19. Compte tenu de sa taille et de son épaisseur, il est difficile d'imaginer qu'elle n'émergeait pas au moins partiellement dans le paysage, marquant ainsi l'emplacement de la tombe. La volonté de signaliser la sépulture était-elle bien à l'origine du dépôt de la dalle au-dessus de la fosse sépulcrale ? D'autres dalles de grès, bien ancrées dans le substrat et naturellement en place, se trouvaient autour de la tombe 19 (fig. 21). Plusieurs de ces dalles furent soulevées pour s'assurer de l'absence de restes humains. Par conséquent le but recherché par les hommes du Néolithique était au contraire peut-être de dissimuler la tombe 19 parmi ces dalles. Malgré un dépouillement bibliographique approfondi, aucun cas comparable n'a été recensé pour le Bassin parisien.

\section{LES MODES DE TRAITEMENT DU CADAVRE}

Les tombes de Changis-sur-Marne ont été classées selon le mode d'inhumation après exclusion des trois cas litigieux correspondant aux sépultures 11, 22 et 23 très érodées. Ainsi deux inhumations sont individuelles et cinq sont plurielles, c'est-àdire multiples ou collectives (tabl. II).

D'un point de vue chronologique les deux sépultures individuelles, relativement anciennes, renvoient au premier tiers du
$\mathrm{IV}^{\mathrm{e}}$ millénaire av. J.-C. Les tombes contemporaines en Bassin parisien sont toujours individuelles à l'instar de la sépulture 137 d'Ivry-sur-Seine (Val de Marne ; Hadjouis, 1998). Cependant, les sépultures rattachées à cet horizon chronologique sont peu nombreuses et sans doute non représentatives des pratiques funéraires des populations qui occupent le territoire à cette époque. D'ailleurs la présence de restes humains dans le comblement de fossés d'enceintes suggère d'autres types de manipulations mortuaires (Pariat, 2007b).

Les cinq tombes plurielles, même si elles ne sont pas strictement contemporaines les unes des autres, peuvent être regroupées au sein d'un même laps de temps entre 3670 et 3370 av. J.-C. Parmi elles deux tombes collectives (sépultures 5 et 20) semblent se placer plutôt au début de cet intervalle, tandis que les trois sépultures doubles $(18,19$ et 21$)$ renvoient plutôt à la fin de la période.

Ces cinq tombes partagent la même caractéristique : elles accueillent exclusivement deux sujets. La présence d'une tombe plurielle, a fortiori double n'a rien d'exceptionnel sur un site néolithique (Chambon et Leclerc, 2007), mais c'est plutôt l'exclusivité du recrutement à partir de 3670 av. J.-C. qui attire l'attention à Changis. Durant cette phase du Néolithique, il est fréquent de rencontrer des sépultures associant deux sujets sur des sites funéraires du Bassin parisien comme à Pont-SainteMaxence (Oise) où un groupe de huit tombes comprend une sépulture double (Bostyn et al., 2004) ; mais la pratique en question ne semble jamais exclure la présence de tombe individuelle. 


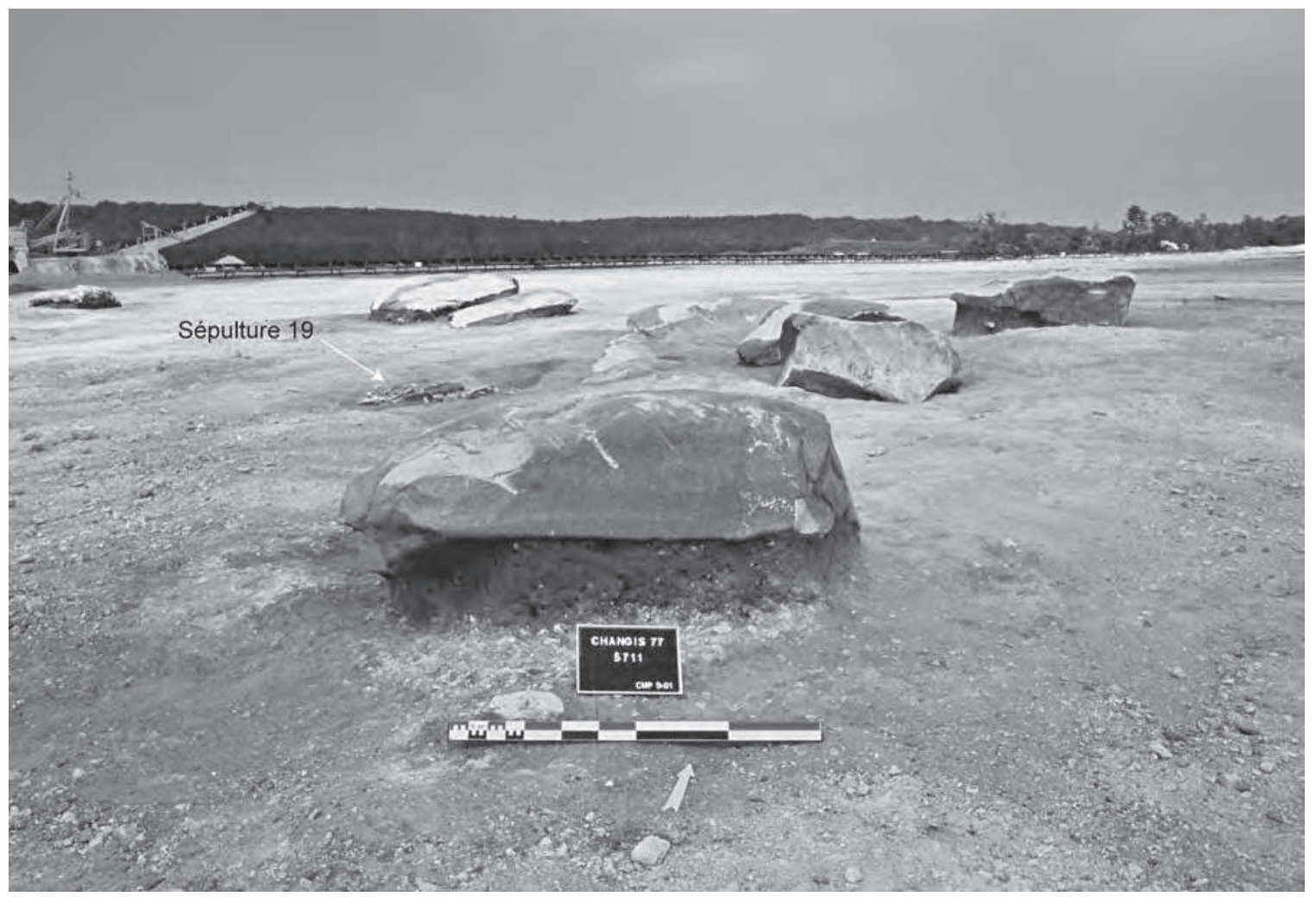

Fig. 21 - Changis-sur-Marne Les Pétreaux, Le Dessus de la Chaussée, vue des dalles retrouvées autour de la sépulture 19 (cliché : F. Lafage, INRAP).

Changis-sur-Marne Les Pétreaux, Le Dessus de la Chaussée, view of the slabs found around Burial 19 (photograph: F. Lafage, INRAP).

\begin{tabular}{|c|c|c|c|c|}
\hline$N^{\circ}$ sep & Individuel & Pluriel & Inconnu & Chronologie \\
\hline 23 & & & $x$ & Phase 1 \\
\hline 31 & $\mathrm{x}$ & & & \\
\hline 14 & $\mathrm{x}$ & & & \\
\hline 11 & & & $\mathrm{x}$ & Phase 2 \\
\hline 20 & & $\mathrm{x}$ & & \\
\hline 5 & & $\mathrm{x}$ & & $\mathrm{Tr}$ \\
\hline 18 & & $\mathrm{x}$ & & \\
\hline 19 & & $\mathrm{x}$ & & \\
\hline 21 & & $\mathrm{x}$ & & Phase 3 \\
\hline 22 & & & $\mathrm{x}$ & \\
\hline
\end{tabular}

Tabl. II - Les types de sépultures.

Types of burial.

\begin{tabular}{|c|c|c|c}
\hline$N^{\circ}$ sep & Mobilier & Position & Chronologie \\
\hline 23 & 1 vase, 1 grattoir & Tête & \\
\hline 31 & 1 tesson & Remplissage & Phase 1 \\
\hline 14 & 1 lame & Remplissage & \\
\hline 20 & 1 vase & Pied sujet B & Phase 2 \\
\hline 5 & 1 massacre cervidé, 1 poinçon os, 15 éclats & Tête sujet B & $\mathrm{Tr}$ \\
\hline 21 & 3 éclats silex & Sur sujet A & Phase 3 \\
\hline
\end{tabular}

Tabl. III - Mobilier retrouvé dans les sépultures.

Grave goods associated with the burials. 
Enfin, le renversement de la pratique d'inhumation observée à Changis pose question. D'après les données radiocarbones, l'inhumation simultanée se substitue à l'inhumation collective. Pourquoi les populations de Changis ont-elle abandonné le recours à la sépulture collective, qui permet pourtant d'optimiser l'espace sépulcral afin d'accueillir de nouveaux défunts ? En effet, il est étonnant qu'aucune sépulture collective n'ait accueilli plus de deux défunts. Peut-être que les tombes collectives de Changis étaient dès le départ conçues comme des structures peu pérennes dans le temps. La pratique de l'inhumation simultanée a pu finir par sembler plus adaptée à ce groupe à une période où, paradoxalement, les sépultures collectives se généralisent en France (Chambon, 2003).

\section{LE DÉPÔT DE MOBILIER ET SON STATUT DANS LES TOMBES}

Six sépultures sur dix ont livré du mobilier (sépultures 5, 14, 20, 21, 23 et 31, tabl. III). Dans trois cas, la tombe renferme plusieurs objets de même nature ou pas, pour certains usagés. Ces vestiges se répartissent en deux vases, un tesson, un outil appointé en os, un massacre de cervidé, un grattoir en silex, une lame en silex, et dix-huit éclats de débitage.

Ces pièces sont apparues dans différents contextes que nous avons ordonnés selon le type de lien entretenu avec le défunt (Chambon et Augereau, 2009). Dans quatre des six cas, des pièces ont été déposées sur le mort ou près de lui. Dans la tombe 5, un outil appointé en os et quinze éclats de silex ont été retrouvés près de la face du sujet $B$. Un vase était au contact du sujet A dans la tombe 20. Dans la sépulture 21, trois éclats de silex se trouvaient sur le sujet $\mathrm{A}$, dans la région du cou et des jambes. Enfin dans la sépulture 23 un vase recouvrait la tête de l'inhumé. Ici il pourrait bien s'agir d'un équipement personnel du défunt.

Une autre situation a été rencontrée dans la sépulture 23. Un grattoir se trouvait en bordure de fosse dans le remplissage. Il est ici bien difficile de discerner la nature volontaire ou non de ce dépôt. Ce constat fait écho aux vestiges découverts dans le remplissage des tombes 14 et 31 .

Enfin reste le cas des objets installés en surface de la tombe, pour lesquels le scénario envisagé est celui d'une désagrégation d'une architecture sépulcrale, qui fait descendre tout ce qui la surmonte. Le massacre de cervidé retrouvé dans la tombe 5 se trouvait sans doute initialement sur un contenant périssable. Le rôle qu'il a pu jouer demeure énigmatique. Peut-être s'agit-il simplement de l'objet qui a servi à aménager la tombe (creusement ? couverture ?) déposé sur le sommet du contenant à titre commémoratif ?

Des trois situations rencontrées à Changis, la position du mobilier par rapport au défunt varie. La nature intentionnelle ou non du dépôt ne peut être que supposée et paraît plus vraisemblable face à des associations étroites à l'instar du poinçon en os de la tombe 5 ou du vase de la tombe 23. Certains objets ont servi avant leur enfouissement ultime, à l'image de cet outil appointé dont l'usure très localisé trahit le travail d'une matière à la fois souple et rigide du type peau sèche. Le dépôt des objets dans la tombe semble donc destiné à rappeler le lien très particulier de l'objet avec le défunt. C'est d'une certaine manière l'expression des sentiments qui transparaît au travers de ces dépôts.
La présence d'objets dans les tombes de la première moitié du $\mathrm{IV}^{\mathrm{e}}$ millénaire av. J.-C. est attestée sur d'autres sites du Bassin parisien dont le recensement reste à faire. Par exemple, à Marolles-sur-Seine Au Levant des Gours aux Lions (Seine-etMarne), les restes d'un vase étaient disposés près de la tête dans la sépulture 45 (Mordant, inédit).

\section{DES TOMBES ET QUEL HABITAT ?}

À Changis, en dehors des tombes aucune autre structure fouillée n'a été rattachée au $\mathrm{IV}^{\mathrm{e}}$ millénaire av. J.-C., ce malgré une surface décapée extensive. Les vestiges d'habitat apparaissent donc absents, à moins que leur mise en évidence ne soit plus délicate que celle des tombes.

En effet, les éventuelles structures domestiques peuvent passer inaperçues a fortiori s'il s'agit de fosses ou de trous de poteau dépourvus de vestiges. Leur caractérisation chronologique devient de fait impossible.

De plus, les multiples occupations, postérieures au Néolithique, au cours de la Protohistoire sont à même d'avoir détruit des structures plus anciennes.

Enfin, les pratiques agraires récentes sont elles aussi sans doute pour partie responsables de l'érosion du site, la pratique du sous solage profond au $\mathrm{xx}^{\mathrm{e}}$ siècle affectant le sous-sol sur parfois près de $1 \mathrm{~m}$ d'épaisseur.

En somme, il est impossible d'affirmer que les tombes de Changis sont isolées, à l'écart de toute zone habitée tant les sources potentielles d'érosion abondent.

La situation rencontrée à Changis trouve des parallèles, bien que peu de sites aient été aussi largement décapés. À Villierssur-Seine Le Gros Buisson (Yonne), six tombes ont été fouillées dans la partie nord-est de l'emprise (Peake dir., 2006). Leur attribution au $\mathrm{IV}^{\mathrm{e}}$ millénaire av. J.-C. est possible grâce aux vases associés aux inhumés et à des datations radiocarbones sur os. Le site de Villiers est, comme Changis, densément occupé durant la Protohistoire, tant et si bien que les éventuelles structures domestiques contemporaines des tombes ont pu passer inaperçues, voir être détruites.

Dans la Bassé auboise, à Pont-sur-Seine La Ferme de l'Isle (Aube), la situation diffère. Lors de la fouille en 2004 d'une portion d'enceinte du Néolithique moyen, treize tombes ont été exhumées dans la partie est (Dugois, 2005). Quelques trous de poteaux, peu profonds, étaient associés à ces différents vestiges. Dans le cas de Pont-sur-Seine, le fossé semble avoir mieux résisté à l'épreuve du temps du fait de sa puissance stratigraphique.

Au final, il paraît bien délicat d'affirmer la spécificité funéraire d'un site comme Changis, car il est impossible de mettre en évidence les structures domestiques, si elles ont existé. En outre, l'exemple du site de Pont-sur-Seine amène à envisager que les sphères domestique et funéraire ne s'excluent pas nécessairement sur un même site.

\section{CONCLUSION}

La fouille extensive sur le long terme de Changis-surMarne illustre parfaitement les difficultés de reconnaissance des ensembles funéraires du $\mathrm{IV}^{\mathrm{e}}$ millénaire av. J.-C. dans 
le Bassin parisien. Les tombes, qui recèlent ici rarement du mobilier chronologiquement typique, ont pu être caractérisées grâce à la réalisation de datations radiocarbones. Sans elles l'entreprise était vouée à l'échec, tant les vestiges funéraires de l'âge du Fer étaient fréquents sur le site.

Les dix tombes de Changis rattachées au $\mathrm{IV}^{\mathrm{e}}$ millénaire av. J.-C. forment un petit corpus, trop hétérogène et restreint pour pouvoir invoquer un millénaire d'évolution de pratiques funéraires au Néolithique moyen. L'analyse des dix sépultures a permis de proposer un phasage en trois grandes étapes couvrant les deux premiers tiers du $\mathrm{IV}^{\mathrm{e}}$ millénaire av. J.-C. Ainsi les sépultures de Changis ne doivent pas être envisagées comme un ensemble unique cohérent et homogène, mais bien comme trois groupes distincts qui se succèdent au cours du temps. Les deux ou trois tombes par phase ne constituent sûrement pas des ensembles complets. L'érosion, parfois importante, des tombes suggère la destruction possible d'autres sépultures. Autrement dit les tombes de Changis constitueraient des «lambeaux » de nécropoles initialement plus vastes.

Enfin, les sépultures de Changis sont localisées dans un secteur de la basse vallée de la Marne où les ensembles funéraires du $\mathrm{IV}^{\mathrm{e}}$ millénaire av. J.-C. ne sont pas légion. Des ensembles contemporains ont été fréquemment découverts au cours de la dernière décennie, en amont de la confluence entre la Seine et l'Yonne. Ces données sont encore largement inédites, et offrent un potentiel documentaire étoffé pour tenter de mieux cerner les pratiques funéraires du quatrième millénaire dans une zone tampon soumise à des influences septentrionales et méridionales, le sud-est du Bassin parisien.

\section{BIBLIOGRAPHIE}

Augereau A., Brunet P., Costa L., Cottiaux R., Hamon T., Ihuel E., Langry-François F., Magne P., Maingaud A., Mallet N., Martineau R., Mille B., Millet-Richard L.-A., Polloni A., Renard C., Richard G., Salanova L., Samzun A., Sidéra I., Sohn M.

2007: «Le Néolithique récent dans le Centre-Nord de la France (3400/3300 2800/2700 av. J.-C.) : l'avenir du Seine-Oise-Marne en question. » in Évin J. (DIR.), Congrès du Centenaire de la Société Préhistorique Française, Avignon, 21-25 septembre 2004, Un siècle de construction du discours scientifique en Préhistoire. "... Aux conceptions d'aujourd'hui », $X X V I^{e}$ Préhistorique de France, Paris, Société Préhistorique Française, p. $165-184$.

BIRKNER R.

1980: L'image radiologique typique $d u$ squelette. Traduit de l'allemend par BlÉRY-LÜFT, revu par BlÉRY M. Édition originale : 1977 (Das typische Röntgenbild des Skeletts. Urban \& Schwarzenberg, München). Maloine, Paris.

Bostyn F., Pinard E., Prodéo F.

2004: " Nouvelle datation de la nécropole de Pont-Sainte-Maxence, Le Poirier ». Internéo, 5, p. 7-15.

Bostyn F., Cayol N., Giligny F., Lo Carmine A, Maigrot Y.

2005 : «Creusement expérimental d'un puits d'extraction de silex sur la minière de Flins-sur-Seine (Yvelines) »,
Mémoires et travaux du Paléoscope $n^{\circ} 1$, Association l'Homme Retrouvé.

\section{BRUZEK J.}

2002: «A method for visual determination of sex, using the human hip bone. ». American Journal of Physical Anthropology, 117, p. 157-168.

Bruzek J., Ferembach D.

1992: «Fiabilité de la méthode visuelle de détermination du sexe à partir du bassin du groupe de travail d'anthropologues européens. Application sur l'os coxal. » Archivio per l'Antropologiae l'Etnologia, 72, p. 145-161.

Bruzek J., Sellier P., Tillier A.-M.

1997: «Varaibilité et incertitude de l'estimation d'âge des non-adultes : le cas des individus morts en période périnatale. » in : Buchet L. (DIR.), L'enfant, son corps, son histoire. APDCA, SofiaAntipolis, p. 187-200.

Bulard A.

1989: Fouille de sauvetage urgent à Dampmart (Seine-et-Marne), "Les Sables » et "Le Champ Breton ». Rapport de fouille, SRA Île-deFrance.

\section{Chambon P.}

2003: La mort dans les sépultures collectives néolithiques en France. Du cadavre aux restes ultimes. $X X X$ Ve supplément à Gallia Préhistoire. CNRS, Paris.

Chambon P., Augereau A.

2009: « Le mobilier en contexte funéraire chasséen dans le Bassin parisien. » in : Collectif, De Méditerranée et d'ailleurs... Mélanges offerts à Jean Guilaine. Archives d'Écologie Préhistorique, Toulouse, p. 191-203.

Chambon P., Leclerc J.

2007: «Les tombes multiples dans le Néolithique français : aléa statistique ou pratique institutionnalisée ? 》 Bulletin de la Société Préhistorique Française, 104, 2, p. 289-306.

Duday $\mathbf{H}$.

1995: «Anthropologie de terrain : archéologie de la mort. » in: Joussaume R. (DIR.), La mort passé, présent, conditionnel. Actes du colloque de la Rochesur-Yon. Groupe Vendéen d'Études Préhistoriques, La Roche-sur-Yon, p. 33-75.

2005: « L'archéothanatologie ou l'archéologie de la mort. » in : Dutour O. (DIR.), Hublin J.-J. (DIR.), VANDERMEersch B. (DIR.), Objets et méthodes en paléoanthropologie. CTHS, Paris, p. 153-217?

Dugois F.

2005 : «Un site néolithique de grande ampleur en Bassée auboise. » Journée archéologique de Champagne-Ardenne, samedi 26 novembre 2005, p. 40-41.

Hadjouis D.

1998: «Sépultures chasséennes et du néolithique final à Ivry - Bords de Seine (Val-de-Marne, France). Résultats radiométriques, anthropologiques 
et paléopathologiques. " Revue Archéologique du Centre de la France, 37, p. 13-31.

Henocq-Pochinot C., Mordant D.

1991 : « La marge sud-est du Bassin parisien : Chasséen et Néolithique moyen. » in : Beeching A. (Dir.)., Binder D. (Dir.), Blanchet J.-C. (Dir.), Constantin C. (DIR.), Dubouloz J. (DIR.), Martinez R. (DIR.), Mordant D. (DIR.), TheVenot J.-P. (DIR.), VAQUer J. (DIR.), Identité $d u$ Chasséen. Actes du colloque international de Nemours, 1989. Mémoires du Musée de Préhistoire d'Île-de-France, $n^{\circ} 4$. Association pour la Promotion de la Recherche Archéologique en Île-deFrance, Nemours, p. 199-210.

Lafage F., Auxiette G., Brunet P., Delattre V., Lanchon Y., Marion S., Martial E., Materne V., Pariat J.-G.

2002: Changis-sur-Marne, "Les Pétreaux» (77). Habitats $d u$ Bronze Final et de La Tène D. Rapport intermédiaire de fouille préventive 9-2001. Direction Régionale des Affaires Culturelles Service régional de l'Archéologie Île-de-France, 2 vols. 166 pages, 168 figures.

Lafage F., Auxiette G., Brunet P., Martial E., Matterne V., Praud I., LAPLANTINE $\mathbf{N}$.

2006: «Premières tentatives d'interprétation spatiale d'un site rural du Bronze final à Changis-sur-Marne (Seineet-Marne). » Bulletin de la Société Préhistorique Française, 103, 2, p. 323-377.

Lafage F., Auxiette G., Brunet P., Delattre V., Le Jeune Y., Martial E., Matterne V., Praud I.

2007: « Changis-sur-Marne « Les Pétreaux »: trois siècles d'évolution d'établissements ruraux de la fin du Bronze final au début du premier Âge du Fer », Bulletin de la Société Préhistorique Française, 104, 2, p. 307-341.

LAFAGE F. (DIR.), LANChON Y. (DIR.)

1998: "Changis-sur-Marne Les Pétreaux (77). Habitats néolithiques et protohistorique. Rapport intermédiaire de fouille préventive (secteur 5). » SRA Ile-deFrance, 2 vols. 146 pages, 204 figures.

Lanchon Y., Bostyn F., Hachem L., Maigrot Y., Martial E., BoitardBidault E.

2008: «Le Néolithique ancien dans la basse vallée de la Marne : l'habitat de Changissur-Marne «Les Pétreaux » (Seine-etMarne). » Revue Archéologique d'Ilede-France, 1, p. 43-94.

LePAGE L.

1980: « Le Camp de la Vergentière à Cohons (Haute-Marne). » in : Collectif,
Préhistoire et Protohistoire en Champagne-Ardenne, Colloque interrégional sur le Néolithique de l'Est de la France, 24-25 mars 1979, Châlonssur-Saône, n spécial, p. 139-165.

MAIGROT Y.

2009: «L'outillage en os, en bois de cerf et sur dent de Clairvaux VII », in : Pétrequin P. (Dir.), Pétrequin A.-M. (DIR.) - Les sites littoraux de Clairvaux (Jura) et le Néolithique moyen Bourguignon. Rapport final de fouilles programmées, vol. II. Laboratoire de Chrono-Environnement UMR 6249. CNRS, Université de Franche-Comté, Besançon, p. 311-333.

MaIGRot Y.

2003: Étude technologique et fonctionnelle de l'outillage en matières dures animales - la station 4 de Chalain (Néolithique final, Jura, France). Thèse de Doctorat, Université de Paris I.

Mordant D.

1967: « Le Néolithique du Gros Bois à Balloy (Seine-et-Marne). » Bulletin de la Société Préhistorique Française, LXIV, $n^{\circ} 2$, p. 347-370.

1987: «Des inhumations en pleine terre ? L'exemple de la Petite Seine. » in : DudAY H. (DIR.), MASSET C. (DIR.) Anthropologie physique et archéologie. Méthodes d'étude des sépultures. Actes du colloque de Toulouse, 4, 5 et 6 novembre 1982, CNRS, Paris, p. $155-166$.

Mordant D., Mordant C.

1972: «L'enceinte Néolithique de Noyensur-Seine (Seine-et-Marne). » Bulletin de la Société Préhistorique Française, 69, 2, p. 554-569.

Moreau C.

2010: La céramique du Néolithique moyen II de l'Yonne à la Saône, entre 4300 et 3400 avant notre ère, Thèse de $3^{e}$ cycle, Université de Bourgogne, 543 p.

Moorrees C.F.A., Fanning E.A., Hunt E.E. 1963: " Age variation of formation stages of ten permanent teeth. " Journal of Dental Research, 42, p. 1490-1497.

Murail P., Bruzek J., Houët F., Cunha E. 2005: «DSP : a tool for probabilistic sex diagnosis using worldwide variability in hip bones measurements. » Bulletins et Mémoires de la Société d'Anthropologie de Paris, n. s., 17, 3-4, p. 167-176.

Pariat J.-G.

2002: «Les sépultures du Néolithique moyen de Changis-sur-Marne - Les Pétreaux (77). » Internéo 4, Journée d'information du 16 novembre 2002, Association pour les Etudes interrégionales sur le Néolithique, p. 99-107. 2007a: «Tombes en coffre et collectivisation des dépôts au Néolithique moyen II à Changis-sur-Marne « les Pétreaux » (Seine-et-Marne). » in : Moinat P. (DIR.), Chambon P. (DIR.), Les cistes de Chamblandes et la place des coffres dans les pratiques funéraires $d u$ Néolithique moyen occidental, actes du colloque de Lausanne, 12-13 mai 2006, Cahiers d'archéologie romande, 110 et Société préhistorique française, mémoire XLIII, p. 91-98.

2007b: Des morts sans tombe ? Le cas des ossements humains en contexte non sépulcral en Europe tempérée entre les $6^{e}$ et $3^{e}$ millénaires av. J.-C, BAR International Series, 1683.

Peake R. (DIR.)

2006: Villiers-sur-Seine "Le Gros Buisson" (Seine-et-Marne, Île-de-France). Habitat aristocratique de la transition âge du Bronze / âge du Fer. Rapport d'opération archéologique, INRAP, Service régional de l'Archéologie Îlede-France.

Pétrequin A.-M., Pétrequin P.

1984: «La Franche-Comté : propositions pour une chronologie interne », in : Pétrequin P. (Dir.), Gallay A. (Dir.), Le Néolithique Moyen Bourguignon (N.M.B.), Actes du colloque de Beffia (Jura, France), juin 1983, Archives suisses d'anthropologie générale, 48,2, p. 17-47.

Poplin F.

1975 : «Problèmes d'ostéologie. » in : LeroIGourhanA., Séminaire sur les structures d'habitat. Sépultures. Collège de France, Ethnologie préhistorique, Paris, p. 27-34.

Roussot-Laroque J.

1991: « L'identité du groupe de Roquefort et le Chasséen dans le sud-ouest atlantique. » in : BEECHING A. (DIR.)., Binder D. (DIR.), Blanchet J.-C. (DIR.), Constantin C. (Dir.), Dubouloz J. (DIR.), Martinez R. (DIR.), Mordant D. (DIR.), Thevenot J.-P. (Dir.), Vaquer J. (DIR.), Identité du Chasséen. Actes du colloque international de Nemours, 1989. Mémoires du Musée de Préhistoire d'île-de-France, $n^{\circ}$ 4. Association pour la Promotion de la Recherche Archéologique en Île-de-France, Nemours, p. 93-107.

Schmitt A.

2005: «Une nouvelle méthode pour estimer l'âge au décès des adultes à partir de la surface sacropelvienne iliaque ». Bulletins et Mémoires de la Société d'Anthropologie de Paris, 17, 2005, p. 89-101.

Scheuer L., Black S.

2000: Developmental Juvenile Osteology. Academic Press, San Diego. 